(2) Open Access Full Text Article

REVIEW

\title{
Reappraisal of the clinical use of leflunomide in rheumatoid arthritis and psoriatic arthritis
}

This article was published in the following Dove Press journal:

Open Access Rheumatology: Research and Reviews

3 November 2010

Number of times this article has been viewed

\author{
Peter BB Jones ${ }^{1,2}$ \\ Douglas HN White ${ }^{2}$ \\ 'Department of Medicine, \\ Faculty of Medical and Health \\ Sciences, University of Auckland, \\ ${ }^{2}$ Rheumatology Department, Waikato \\ Hospital, Hamilton, New Zealand
}

Correspondence: Peter Jones Waikato Clinical School, Peter Rothwell Academic Centre, Private Bag 3200, Hamilton 3040, New Zealand

Tel +64078398750

Fax+640783987/2

Email p.jones@auckland.ac.nz

\begin{abstract}
Leflunomide is a disease-modifying antirheumatic drug (DMARD) that has been in routine clinical use for the treatment of rheumatoid arthritis (RA) and psoriatic arthritis for a decade. In RA, clinical trials of up to two years' duration showed that leflunomide monotherapy was equivalent to methotrexate in clinical and radiographic disease outcomes (tender and swollen joint counts, physician and patient global assessments, American College of Rheumatology and Disease Activity Score responses, slowing or halting of radiographic progression). In a number of studies, quality of life measurements indicated that leflunomide is superior to methotrexate. Leflunomide has been studied in combination with methotrexate and shows efficacy in patients only partly responsive to this agent. Recent trials have shown that leflunomide can be used safely with biologic DMARDs, including antitumor necrosis factor agents and rituximab as part of the treatment algorithm in place of methotrexate as a cotherapy. Leflunomide has demonstrated efficacy as a monotherapy in psoriatic arthritis, and it also has a beneficial effect in psoriasis. Postmarketing studies have shown that retention on treatment with leflunomide is equal to methotrexate and superior to other DMARDs. In general, its side effect profile is acceptable compared with other DMARDS, with nausea, diarrhea, and hair fall occurring commonly, but only rarely leading to discontinuation. Liver toxicity is the most significant problem in clinical use although it is uncommon. Peripheral neuropathy, hypertension, pneumonitis, and cytopenia occur more rarely. Leflunomide is contraindicated in pregnancy and should be used with caution in women during child-bearing years. In this review, the place of leflunomide in therapy is discussed and practical advice informed by evidence is given regarding dosing regimens, safety monitoring, and managing side effects. Leflunomide remains one of the most useful of the nonbiologic DMARDs.
\end{abstract}

Keywords: evidence-based practice, review, disease-modifying antirheumatic drugs, safety, efficacy, leflunomide, rheumatoid arthritis, psoriatic arthritis

\section{Introduction}

Leflunomide was last the subject of a review of clinical use in $2006^{1}$ and has more recently been the subject of a benefit-risk analysis. ${ }^{2}$ Major changes in disease management have occurred, with a focus on achieving remission in inflammatory arthritis through frequent assessment driving treatment changes, use of combinations of diseasemodifying antirheumatic drug (DMARD) therapies and the early use of biologic agents. The challenges in treating rheumatoid arthritis (RA) and psoriatic arthritis relate to the unpredictability of response to treatment, the frequent occurrence of dose-limiting side effects, and rarer serious adverse reactions requiring cessation of treatment. There remains an unmet need for a greater range of DMARDs, and for drugs that provide an alternative to methotrexate as baseline therapy, particularly for use in combination 
with biologic DMARDs, such as antitumor necrosis factor $\alpha$ (anti-TNF) agents and rituximab. In many countries, access to these very expensive drugs is limited, and the use of traditional DMARDs, including leflunomide, remains a key strategy. This review incorporates new information about the clinical use of leflunomide in RA and psoriatic arthritis, places it in the context of existing knowledge of the drug and takes an evidence-based practice approach to give practical advice regarding the use of leflunomide in clinical situations.

\section{Chemistry, pharmacology, and mechanism of action}

Leflunomide is an immunomodulatory and anti-inflammatory drug initially developed and tested in animal models of autoimmunity and transplant medicine. ${ }^{3}$ It is an isoxazole derivative, freely soluble in water, and almost completely absorbed by the gut. Leflunomide is a prodrug having little or no immunomodulatory activity until nonenzymatic conversion to the active metabolite, teriflunomide (A77 1726), probably within the gut wall and liver. ${ }^{4}$ In the plasma it is highly (>99\%) protein-bound. It demonstrates linear pharmacokinetics in doses up to $100 \mathrm{mg}$, with peak plasma concentrations of teriflunomide being reached in 6-12 hours. ${ }^{5}$ The plasma half-life is approximately 15 (range 5-40) days, ${ }^{6}$ but this is reduced to 1-2 days by cholestyramine or activated charcoal washout, implying significant enterohepatic recirculation. This can result in significant plasma levels being maintained for up to two years after stopping treatment. Teriflunomide is an inhibitor of cytochrome P450 2C9 in vitro, conferring a risk of drug interactions, particularly with warfarin, phenytoin, and tolbutamide. ${ }^{5}$ Rifampicin increases teriflunomide levels about $40 \%$ by an unknown mechanism, and leflunomide displaces nonsteroidal anti-inflammatory drugs (NSAIDs) from plasma proteins. The clinical significance of these effects is uncertain..$^{5}$ Leflunomide is excreted in roughly equal proportions in urine and bile, but teriflunomide levels are not affected significantly by hemodialysis. ${ }^{7}$ There is no evidence of accumulation in renal failure, although the free fraction of teriflunomide is increased, and so dose reduction should not be needed. However, studies have not addressed this issue, and caution is advised when using leflunomide in renal impairment. ${ }^{5}$

Leflunomide has a weak uricosuric effect in the proximal tubule, and significant falls in serum uric acid were observed in trials. ${ }^{8}$ Hyperuricemia has been linked to hypertension in RA, ${ }^{9}$ but paradoxically, despite its urate-lowering effect, leflunomide is associated with an increase in blood pressure. The mechanism of this effect is unknown but it may be renally mediated, possibly through an effect on anion exchange in the proximal tubule, an increase in sympathetic drive, or by increasing the salt and water retention caused by NSAIDs.

The principal mechanism of action is by inhibition of the mitochondrial enzyme dihydro-orotic acid dehydrogenase (DHODH), which catalyses a key step in the de novo metabolic pathway of pyrimidine synthesis. T lymphocytes depend on this to supply the large increase in ribonucleic acid precursors necessary for their proliferation. As a result, lymphocytes become depleted of ribonucleotide precursors (principally rUMP) reducing DNA and RNA synthesis and resulting in the arrest of cell proliferation in the G1 phase of the cell cycle. ${ }^{10,11}$ Other body cells (eg, gastrointestinal, hemopoietic) are able to use the salvage pathway as a supply of uridine for pyrimidine synthesis, which probably explains the relative lack of unwanted effects of leflunomide on cell proliferation in other body systems, such as cytopenia or mucositis. ${ }^{12}$ The relevance of this mechanism of action is supported by pharmacogenomic studies showing that people with a common missense polymorphism of the DHODH gene sequence have lower remission rates on leflunomide than those with the usual allele. ${ }^{13}$ Polymorphism of the DHOHD gene is also implicated in the cytochrome P1A2-mediated liver toxicity of leflunomide. ${ }^{14}$

A multitude of additional mechanisms of action have been proposed, including the inhibition of tyrosine kinases, ${ }^{15}$ reduction in growth factor synthesis and interleukin $2,{ }^{16}$ inhibition of lymphocyte adhesion to synovial high endothelial venules, ${ }^{17}$ inhibition of neutrophil and macrophage migration, ${ }^{18}$ inhibition of adhesion molecules and matrix metalloproteinases, ${ }^{19-21}$ and reduction in phospholipase $\mathrm{A} 2$ activation products, such as prostaglandins and leukotrienes. ${ }^{3}$ While some of these mechanisms have been shown to operate in synovial tissue, most are thought unlikely to be significant contributors to the mechanism of action at the tissue concentrations achieved by the doses used for clinical indications.

\section{Clinical studies in rheumatoid arthritis}

The great majority of clinical studies have been conducted in RA, and there has been only one randomized controlled trial of leflunomide in psoriatic arthritis. The justification for the use of leflunomide in this condition and in other forms of inflammatory polyarthritis follows a heuristic argument. A 2003 Cochrane review of six clinical trials in RA, ${ }^{22}$ updated in 2009 with 33 studies published to June $2008,{ }^{23}$ concluded that "leflunomide improves all clinical outcomes and delays radiographic progression at both six and 12 months compared 
with placebo", and commented that "its efficacy and adverse events at 2 years of treatment are comparable to sulfasalazine or methotrexate". It was not possible to tell whether treatment outcomes were better or worse than those obtained with sulfasalazine or methotrexate because no significant differences were seen in the primary clinical outcome measures between the active treatment groups in the clinical trials.

\section{Leflunomide as monotherapy}

The efficacy of leflunomide in RA was tested in a Phase II trial $^{6}$ and established in three double-blind, randomized, 6-12 month, Phase III clinical trials. ${ }^{8,24-26}$ It was compared with methotrexate ${ }^{25}$ and sulfasalazine ${ }^{8}$ in two placebo-controlled trials and with methotrexate in an active comparator trial against methotrexate. ${ }^{24}$ The sulfasalazine trial lasted six months and the methotrexate studies for 12 months. These studies enrolled patients who had received previous DMARDs, as well as those who were DMARD-naive. The Phase II trial was a dose-ranging study in which subjects received placebo or leflunomide $5 \mathrm{mg}, 10 \mathrm{mg}$, or $25 \mathrm{mg}$ daily; a single loading dose was given, $50 \mathrm{mg}$ for the $5 \mathrm{mg}$ group and $100 \mathrm{mg}$ for the 10 and $25 \mathrm{mg}$ groups. There was a clear clinical dose response, with the $25 \mathrm{mg}$ dose being superior to $10 \mathrm{mg}$ and the $5 \mathrm{mg}$ dose being ineffective. ${ }^{6}$

In the Phase III trials, a loading dose of leflunomide $100 \mathrm{mg}$ taken on each of the first three days was used, followed by a maintenance dose of $20 \mathrm{mg}$ daily. The dose of sulfasalazine was $1 \mathrm{~g}$ twice daily, while methotrexate dosing was initially $7.5 \mathrm{mg} /$ week, titrated up to $15 \mathrm{mg} /$ week, and $53 \%-60 \%$ of patients took $15 \mathrm{mg} /$ week from week 9 . These doses of methotrexate were those most commonly used at the time, although lower than in current practice. In the placebo-controlled methotrexate study, folic acid supplements of 1-2 mg daily were given per protocol and taken by $98 \%$ of participants, but in the active comparator trial, folic acid supplementation was optional and used by only $11 \%$, usually after an adverse event had occurred. In contrast with other reports, ${ }^{27,28}$ adverse events due to methotrexate were no more likely in the patients not taking folic acid supplements. However, there was some evidence that folic acid reduced the efficacy of methotrexate. The tender joint count, swollen joint count, and both the physician and the patient global assessments were significantly more improved by methotrexate than by leflunomide in the study without folic acid given per protocol, whereas in the study where folic acid supplementation was mandatory, leflunomide showed greater improvements in these outcomes. Several reports and reviews have concluded that higher doses of methotrexate are required to achieve a given clinical outcome in the presence of folate supplementation, ${ }^{28-30}$ so this discrepancy, combined with the rather low doses of methotrexate used, suggests that there was some bias in these trials in favor of leflunomide.

The primary outcome measure in these studies was the American College of Rheumatology (ACR) 20 response at study endpoint; ACR 50 and ACR 70 were also recorded. Summarized results of the studies are shown in Figure 1.

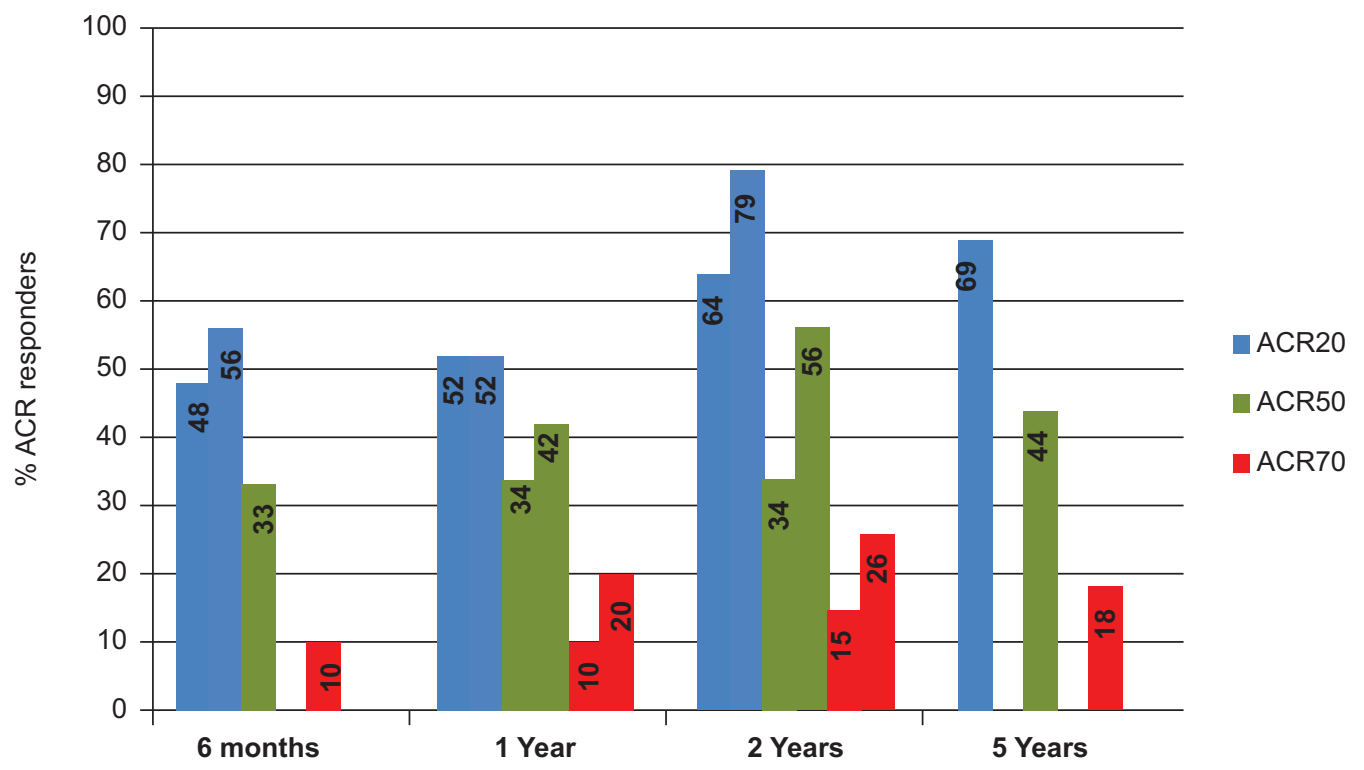

Figure I Range of American College of Rheumatology responder rates from different clinical studies of leflunomide. Data at six months and one year are taken from doubleblind randomized placebo and active comparator-controlled clinical trials.,24,25 Patients completing 12 months were re-enrolled to a year 2 cohort and remained blinded to treatment allocation. ${ }^{33-35}$ Those completing two years were eligible to enroll in an open-label, non-controlled extension study to complete five years of treatment. ${ }^{37}$ 
The mean time to initial response (ACR 20) was about eight weeks, and maximal responses were seen by 12 weeks, ${ }^{25}$ although DAS28 (Disease Activity Score including a 28 -joint count) clinical responses continued to increase over the first six months of therapy in a sulfasalazine trial (Figure 2). ${ }^{31}$ Improvement in all clinical outcome measures (tender and swollen joint counts, patient and physician global assessments) occurred earlier with leflunomide than with sulfasalazine. Quality of life as assessed by the Health Assessment Questionnaire Disability Index (HAQ DI) was significantly improved by leflunomide as compared with placebo and to a similar degree as methotrexate (improvement in HAQ DI of 0.29 for leflunomide and 0.26 for methotrexate). ${ }^{26}$ Analysis of results for other quality of life measures, ie, the Medical Outcomes Survey Short Form-36 (SF-36) and the weighted top five problem elicitation technique, suggested that leflunomide was superior to methotrexate for these outcomes. ${ }^{25,26,32}$

\section{Long-term studies}

Long-term follow-up extension studies of the monotherapy trials confirmed durability of effects in patients who had responded to initial treatment. ${ }^{33,34}$ Clinical ACR responses, radiographic progression, and quality of life indices all showed sustained improvement. Eighty-five percent of leflunomide-treated patients and $79 \%$ of the methotrexatetreated patients remained on active treatment for two years. ${ }^{33}$ In the extension studies, the dose of methotrexate could be escalated to $20 \mathrm{mg} /$ week if clinically indicated. No difference was seen in maintenance of clinical improvement between leflunomide and methotrexate, but responses to sulfasalazine waned. There was an emergent difference compared with methotrexate in the second year in favor of leflunomide in quality of life and physical function indices between the active comparator drugs. In a two-year follow-up of the sulfasalazine trial, HAQ DI fell by a mean 0.65 in the leflunomide arm compared with 0.36 for sulfasalazine and no change for placebo. ${ }^{35}$ Study participants receiving leflunomide showed improvement in SF-36 scores that approached US population norms over 12 and 24 months (Figure 3 ). ${ }^{25,26,33}$ Radiographic analysis showed that patients responsive to leflunomide in the first year experienced a halting of disease progression in the second year. ${ }^{36}$

An open-label extension study of 214 patients still responding at two years in two Phase III trials was conducted until leflunomide was marketed, with a mean treatment duration of 4.6 years. ${ }^{37}$ Efficacy results by ACR responses showed that improvement seen at one year was maintained for up to five years (ACR 20 responses remained around 70\%, ACR 50 at $50 \%$ and ACR 70 at 20\%. [See Figure 1]). Functional ability and quality of life improvements were also maintained, and there were no new treatment-emergent side effects.

\section{Remission}

Remission is an increasingly realistic goal in RA, and has been defined by the US Food and Drug Administration (FDA), ${ }^{38}$

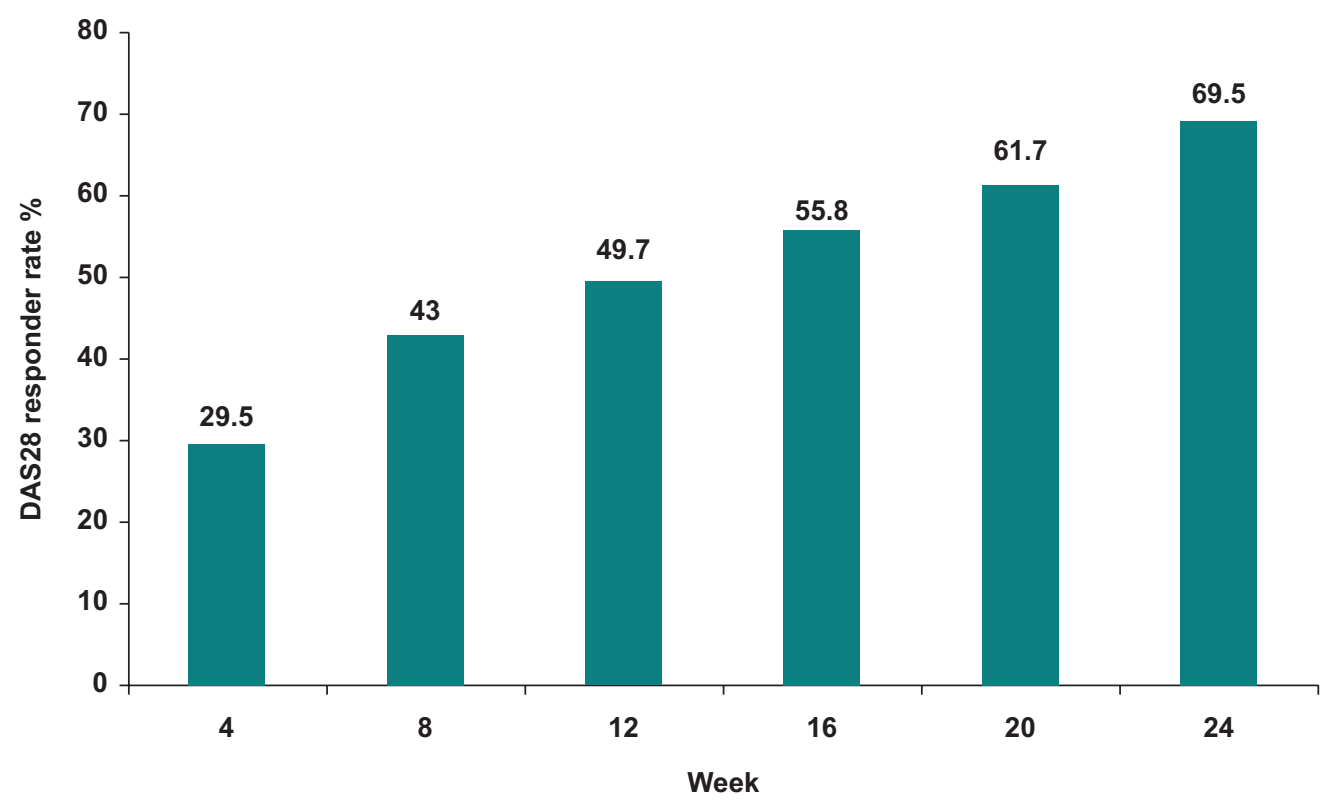

Figure 2 Sustained DAS28 response over time for leflunomide $20 \mathrm{mg}$ daily following a loading dose of 100 mg daily for three days (percentage of patients with a response maintained to 24 weeks). Data from the RELIEF study. ${ }^{51}$

Abbreviation: DAS 28, Disease Activity Score 28 joint count. 


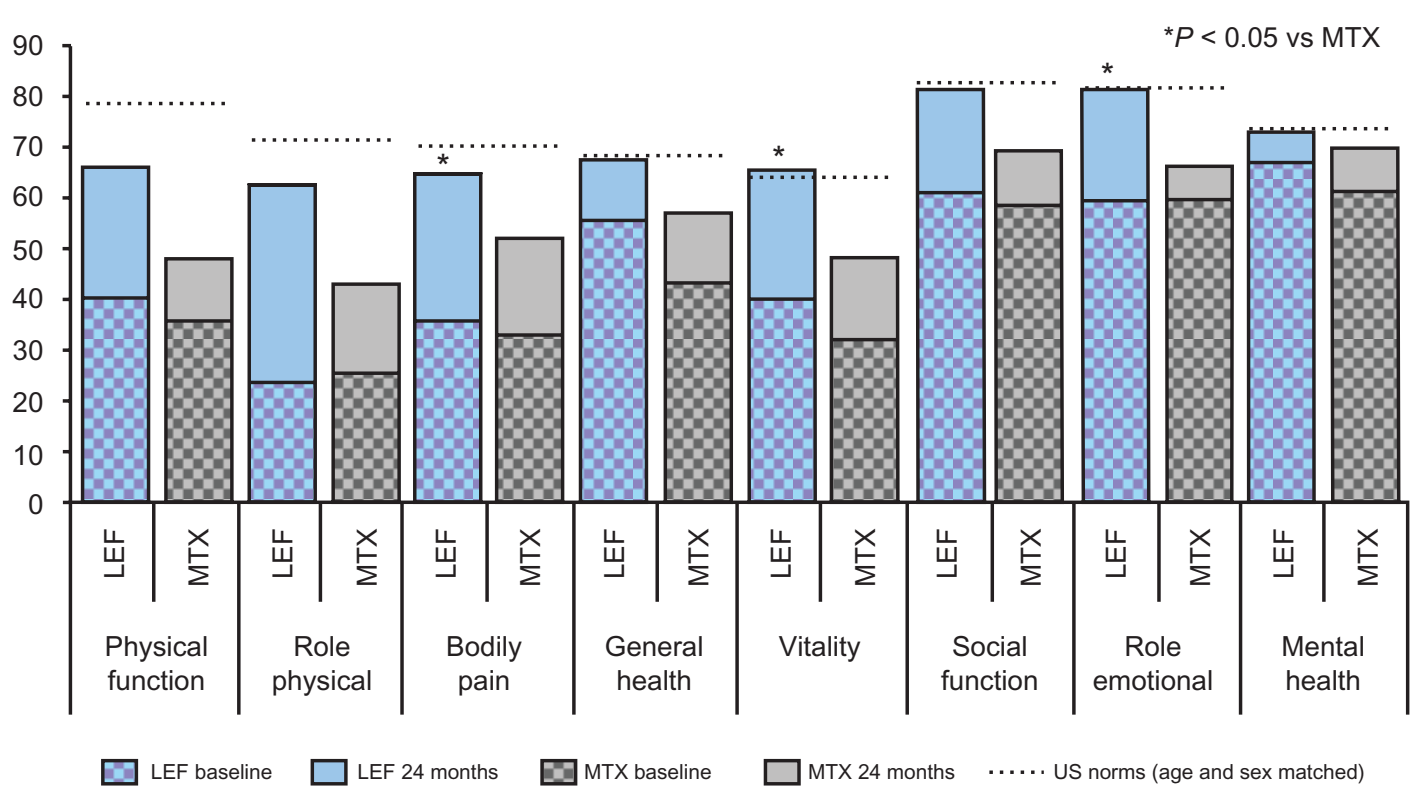

Figure 3 Quality of life changes in randomized controlled trials of LEF versus MTX over two years assessed by Medical Outcomes Survey Short Form 36 (SF-36). Vertical bars show baseline and 24-month data for each domain of the SF-36, dashed horizontal lines show US population norms. ${ }^{143}$

Abbreviations: LEF, leflunomide, MTX, methotrexate.

the ACR, ${ }^{39,40}$ and the European League Against Rheumatism (EULAR). ${ }^{41}$ Using data from clinical trials, remission rates according to these definitions have been calculated in post hoc analyses. ${ }^{42}$ Methotrexate, gold, penicillamine, and sulfasalazine showed remission rates of between $7 \%$ and $22 \%$, while leflunomide showed EULAR remission rates between $13 \%$ and $20 \%{ }^{31,43}$ Combination therapies can show remission rates of up to $42 \%$, and biologic drugs in combination with methotrexate $31 \%-50 \%$.

\section{Effect on structural joint damage}

Radiographic arms of the studies assessed erosions by Sharp score and demonstrated a slowing of disease progression by leflunomide, sulfasalazine, and methotrexate compared with placebo. ${ }^{8,36,44}$ While improvements were shown for the comparison with placebo, treatment responses were not different between the active comparators in these Phase III registration trials. A long-term analysis of 128 patients treated for a mean of 4.3 years showed that one-third of patients treated with leflunomide had no radiographic progression. ${ }^{45}$ In a study primarily designed to show the validity of digital X-ray radiogrammetry and computer-aided joint space analysis as diagnostic tools to quantify radiographic changes occurring over time in RA, 40 patients taking either methotrexate or leflunomide were studied. ${ }^{46}$ The study was not randomized, but the patient characteristics were well matched between the treatment groups. Patients taking methotrexate $15 \mathrm{mg}$ weekly showed more joint space loss and demineralization than those taking leflunomide $20 \mathrm{mg}$ daily. These results suggest a strong effect on halting of joint damage by leflunomide, to at least the same extent as methotrexate.

\section{Summary of registration studies}

The registration studies for leflunomide in RA are important for several reasons. They are the last placebo-controlled studies that will ever be done in patients with active RA. They were the first well designed studies to show conclusively that DMARDs are disease-modifying in terms of radiographic progression. The trials enrolled high proportions of patients with early disease $(40 \%-45 \%$ had disease duration of between six months and two years) and of patients who were DMARD-naive (33\%-47\%). The placebo arms of the trials also give a benchmark for radiographic progression in early and established RA (other studies have used cross-sectional data to demonstrate erosive progression). Leflunomide was approved in 1999, a golden year in rheumatology that also saw the approval of the anti-TNF agents, infliximab and etanercept.

\section{Leflunomide in combination with nonbiologic DMARDS} Methotrexate

Methotrexate and leflunomide have different but complementary effects on the inflammatory immune pathway. Methotrexate inhibits cytokine production and purine synthesis and 
causes the release of adenosine, whereas leflunomide affects de novo pyrimidine synthesis, thereby regulating lymphocyte proliferation. This provides a biochemical basis for combination therapy in RA. ${ }^{47}$ Combination treatment using methotrexate and leflunomide has been assessed in two Phase III trials. Patients with an inadequate response to methotrexate had leflunomide added to their treatment.

In a small open-label study of 30 patients $^{48}$ leflunomide $10 \mathrm{mg}$ daily was added to methotrexate without a loading dose; $53 \%$ of patients achieved ACR 20 and 38\% achieved ACR 50 at 12 months. No pharmacokinetic interactions were noted. In a larger, double-blind, placebo-controlled study of 263 patients with active disease despite methotrexate, dosed at $15-20 \mathrm{mg} /$ week for at least six months, the combination of methotrexate with leflunomide $100 \mathrm{mg}$ for two days followed by $10 \mathrm{mg}$ daily was studied. The addition of leflunomide was superior to methotrexate plus placebo; at 24 weeks the ACR 20 response rate was $46.2 \%$ versus $19.5 \%$; and ACR 50 response rate $26.2 \%$ versus $6.0 \%$ for placebo (Figure 4$).{ }^{49}$ Health-related quality of life measures and physical functioning were improved significantly by combination treatment but not by methotrexate-placebo. Discontinuation rates and side effects did not appear to be increased in the combination therapy treatment group.

A 24-week, open-label extension study enrolled 192 patients in which those receiving methotrexate-placebo were switched to methotrexate-leflunomide $10 \mathrm{mg}$ daily while those already on the combination continued their treatment. ${ }^{50}$ In contrast with the original leflunomide cohort, a loading dose was not given. This enabled the clinical response and side effect profile of use of a loading dose to be examined. ACR response rates were maintained by those remaining on combination therapy, while those switching from placebo-methotrexate showed improvements in clinical outcomes and health-related quality of life similar to the original cohort. Therefore, there is a lack of evidence that using a loading dose of leflunomide improves clinical responses at 24 weeks when adding the drug to methotrexate.

\section{Sulfasalazine}

In the RELIEF study, leflunomide was studied in combination with sulphasalazine. ${ }^{31,51}$ Following 24 weeks of open-label leflunomide, nonresponders were randomized to sulfasalazine monotherapy or to sulfasalazine-leflunomide in a 24-week, double-blind, and placebo-controlled phase. The study did not show a difference between the treatment groups, but was underpowered because of a higher than predicted responder rate in the initial phase of the trial. At six months, $70 \%$ achieved a DAS28 response, 61\% had an ACR 20 response, $25 \%$ had a low DAS $(<3.2)$, and $13 \%$ were in remission, ${ }^{31}$ confirming the results from other Phase III trials. The time course of the ACR 20 response is shown in Figure 2. In the sulfasalazine-leflunomide versus sulfasalazine part of the trial, a trend towards better DAS outcome with the combination was observed but this was not statistically significant. The leflunomide-sulfasalazine combination appeared to be as well tolerated as monotherapy.

\section{Leflunomide in combination with biologic DMARDs Anti-TNF agents}

Methotrexate is usually coprescribed with anti-TNF agents and has been shown to improve clinical response rates in RA, a practice supported by several randomized controlled trials using etanercept, infliximab, or adalimumab ${ }^{52-55}$ and supported by a large population-based study. ${ }^{56}$ Retention on therapy

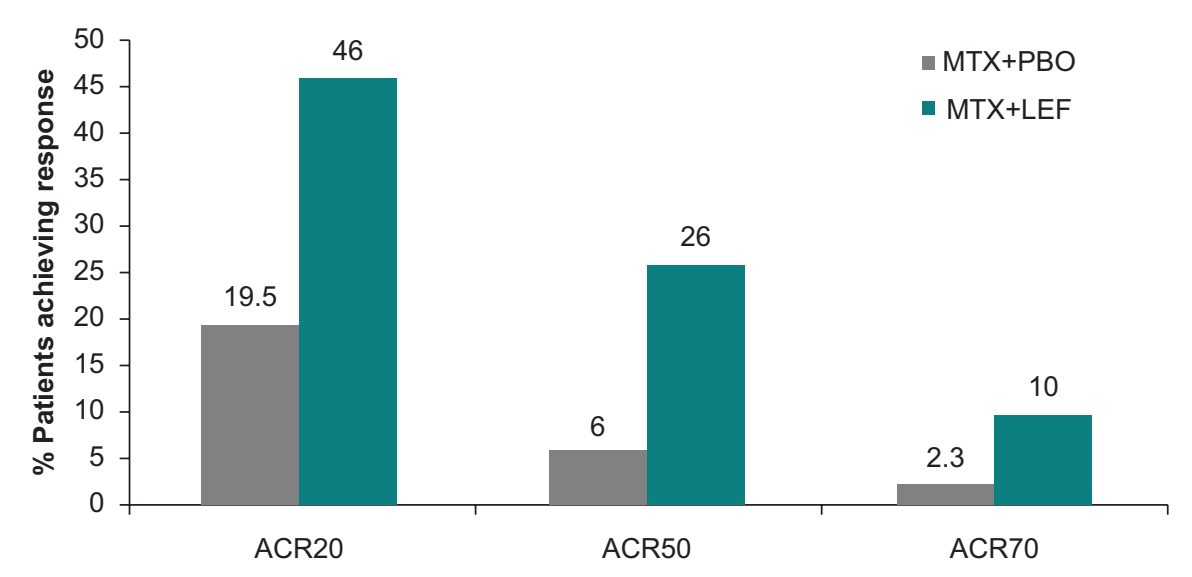

Figure 4 American College of Rheumatology response rates for combination therapy of leflunomide plus methotrexate versus methotrexate plus placebo.49 Abbreviations: MTX, methotrexate; PBO, placebo; LEF, leflunomide. 
is also higher for methotrexate-anti-TNF than for anti-TNF monotherapy. ${ }^{57,58}$ This combination has a side effect profile similar to anti-TNF agents used alone. However, enhanced clinical responses have only been shown in RA; methotrexate is not usually coprescribed with anti-TNF agents being used for psoriasis, Crohn's disease, or ankylosing spondylitis, even though methotrexate is used as primary therapy for most of these indications.

In patients intolerant or nonresponsive to methotrexate, other DMARDs have been used to increase the efficacy of anti-TNF agents, despite a relative lack of evidence for efficacy from prospective, randomized, and blinded trials. Two randomized controlled trials studied the effect of adding etanercept to sulfasalazine compared with continuing either treatment alone in patients with active disease despite sulfasalazine. ${ }^{59,60}$ Clinical outcomes were equal whether etanercept was used as monotherapy or in combination with sulfasalazine, and both were superior to continued sulfasalazine monotherapy. Likewise, clinical outcomes were equivalent between a range of conventional DMARDs, including leflunomide used as cotherapy with adalimumab. ${ }^{61,62}$

\section{Observational studies}

After methotrexate, leflunomide is the most commonly prescribed cotherapy with anti-TNF agents. ${ }^{63}$ Leflunomide has been used in a number of open-label studies of varying quality, and reports from registries confirm this use in practice. ${ }^{58,63-73}$ In these observational studies, an anti-TNF agent was added to leflunomide following stabilization of treatment and an inadequate response. The general conclusion has been that the combination is generally safe, and methotrexate and leflunomide appear to have equivalent efficacy in combination with anti-TNF agents. However, few studies have addressed the issue of relative efficacy in a formal analysis.

Some nonrandomized retrospective studies have suggested that leflunomide is less effective and associated with more side effects compared with methotrexate used in combination with infliximab. One prospective study suggested an increased incidence of serious adverse events, in particular severe skin reactions and immune-mediated side effects, including appearance of antibodies and severe infections, and a lower effectiveness compared with methotrexate. ${ }^{62}$ Patients given leflunomide are usually intolerant or nonresponsive to methotrexate and may be at a higher baseline risk of developing side effects (a channeling effect) and to have poorer responses to treatment, so conclusions are hard to draw.
A prospectively enrolled Swiss registry study compared the retention rate, effectiveness and safety of leflunomide with other conventional DMARDs, including methotrexate, as cotherapy with anti-TNF agents in 1218 patients with RA. ${ }^{74}$ Hazard analysis was used to analyze discontinuation rates and the incidence of toxicities as indicators of effectiveness, and longitudinal regression modeling was used to analyze radiographic progression, disability, and disease activity scores. There was no difference in retention on therapy between different groups. The discontinuation rate was high, with patients remaining on the combinations for a mean of only 16 months. This rate is substantially higher than that of anti-TNF agents used as monotherapy. Apparent differences in retention rates in favor of methotrexate disappeared when confounding variables were accounted for. There were no significant differences in response to treatment among the groups as assessed by radiographic progression, change in functional disability score, or RA disease activity scores. However, all groups improved over baseline. Twenty-eight percent of patients using combination therapies had treatment stopped because of adverse events, principally due to allergy, infection, rash, and gastrointestinal intolerance. Hepatotoxicity was an uncommon reason for discontinuation. There were no differences in tolerability or safety profile between the treatment groups, apart from a lower reported rate of allergy in the methotrexate-anti-TNF group. The authors concluded that they could detect no difference in drug retention rates or effectiveness in patients using anti-TNF agents with methotrexate, leflunomide, or other nonbiologic DMARDs.

A similar analysis was performed by a German group reporting on the biologics registry, RABBIT, in which responses to individual anti-TNF agents was examined. ${ }^{75}$ Disease activity and treatment data were analyzed from 1769 patients treated with adalimumab, etanercept, or infliximab in combination with either methotrexate or leflunomide over 36 months. Discontinuation rates at 36 months for antiTNF-methotrexate combinations were $46.3 \%$ for etanercept, $51.3 \%$ for adalimumab, and $61.5 \%$ for infliximab. For antiTNF-leflunomide, discontinuation rates were $53.4 \%$ for etanercept, $63.1 \%$ for adalimumab, and $67.1 \%$ for infliximab. However, patients treated with leflunomide combinations had a higher baseline disease activity score. This was highest in the leflunomide-infliximab group, which also had the highest discontinuation rate. EULAR response rates at 24 months were $74 \%-81 \%$ for methotrexate and $72 \%-81 \%$ for leflunomide combinations. The results support the use of leflunomide in combination with anti-TNF agents where methotrexate is contraindicated, not tolerated, or lacks efficacy. 


\section{Randomized study}

A recent prospective randomized study involving 120 subjects compared methotrexate or leflunomide in combination with adalimumab, infliximab, or etanercept. ${ }^{76}$ Patients with high disease activity despite treatment with either methotrexate or leflunomide were followed for 24 weeks and assessed by ACR 20, 50, and 70 responses and by DAS28-ESR (erythrocyte sedimentation rate). There were no efficacy differences between the leflunomide or methotrexate combination groups or any of the six treatment subgroups. Quality of life improvements assessed by modified HAQ exceeded the minimum clinically important difference ${ }^{77}$ in all treatment allocation groups at equal time points (Figure 5). Mild side effects occurred more commonly with methotrexate (43.3\%, mostly nausea) than with leflunomide $(21.6 \%$, mostly hypertension, weight loss, and diarrhea). Sixteen patients discontinued because of serious side effects. There was no difference overall between the groups in rates of discontinuation, and although more patients discontinued due to serious side effects with the leflunomide combinations, this was not statistically significant. It appears that there is a similar probability of achieving clinical improvement between methotrexate and leflunomide when used in combination with anti-TNF agents.

\section{Other biologic DMARDs}

Leflunomide is starting to be used in place of methotrexate in combination with other biologic DMARDs, such as rituximab, and appeared to be effective in a small case series. ${ }^{78} \mathrm{~A}$ larger multicenter study of 1901 patients compared rituximab alone or in combination with either methotrexate or leflunomide over one year. Despite patients in the combination treatment groups having higher baseline DAS28 values, significantly more patients treated with rituximab-leflunomide achieved a EULAR "good response" at six months (33\%) than those treated with rituximab-methotrexate $(21 \%)$ or rituximab alone $(20 \%) .{ }^{79}$ Leflunomide has also been used with anakinra, ${ }^{80,81}$ but the effect of leflunomide in combination with other biologic DMARDs, such as tocilizumab or abatacept, has not been formally assessed.

\section{Clinical studies in psoriatic arthritis and other inflammatory conditions Psoriatic arthritis}

In comparison with the published data on leflunomide in RA, there is a paucity of research in psoriatic arthritis, with only one 24-week Phase III trial in 190 subjects with active psoriatic arthritis and psoriasis. ${ }^{82}$ Study participants had at least $3 \%$ of the skin surface involved with psoriasis. After randomization, they received placebo or a $100 \mathrm{mg}$ per day loading dose of leflunomide for three days followed by $20 \mathrm{mg}$ daily. Leflunomide showed good efficacy for psoriatic arthritis and also showed a significant benefit for psoriasis. Fifty-eight of 95 participants taking leflunomide achieved the primary outcome of a psoriatic arthritis ACR response (PS-ACR) (a composite outcome measure comprising

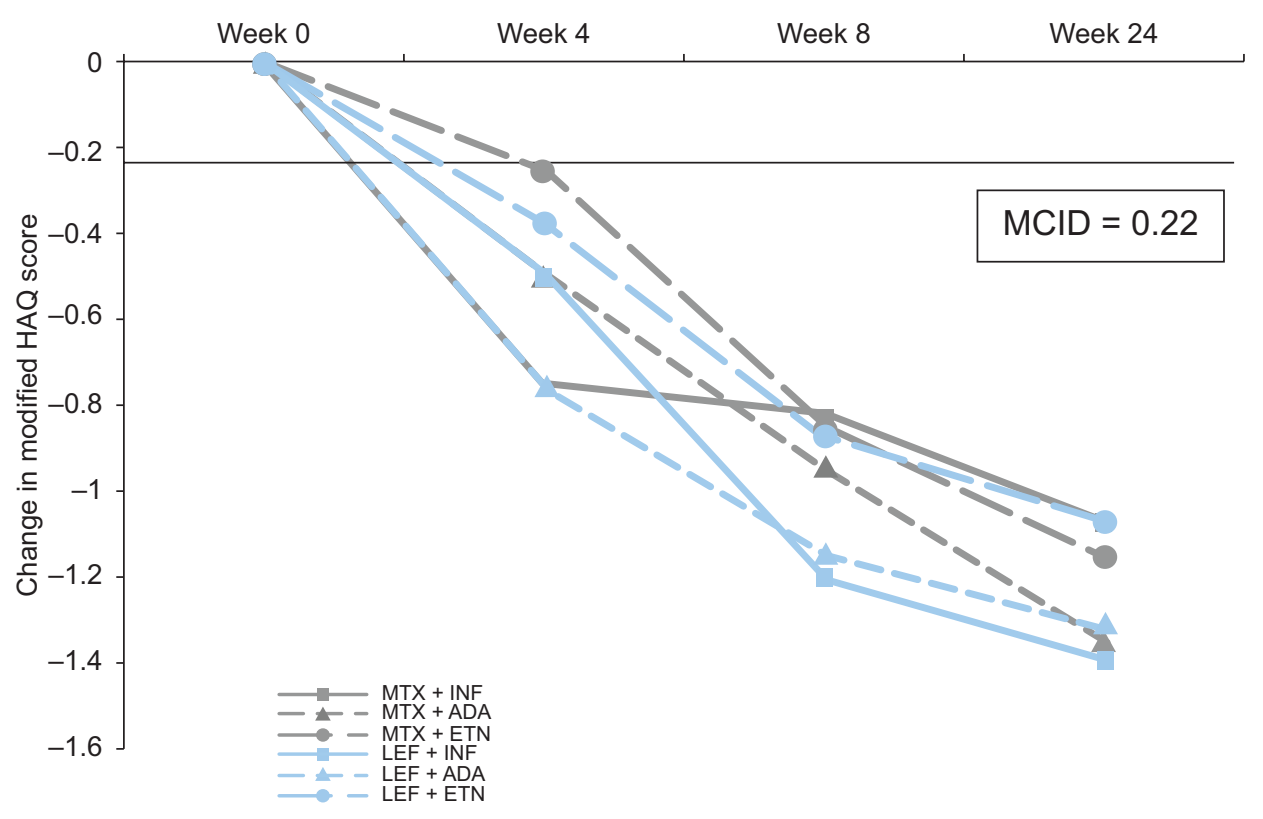

Figure 5 Change in quality of life occurring over time by treatment allocation with biologic DMARDs in combination with methotrexate or leflunomide. ${ }^{76}$ Abbreviations: ADA, adalimumab; ETN, etanercept; INF, infliximab; LEF, leflunomide; MTX, methotrexate; MCID, minimum clinically important difference; ${ }^{77}$ mHAQ, modified Health Assessment Questionnaire; DMARDs, disease-modifying antirheumatic drugs. 
clinical, biochemical, and function components validated for psoriatic arthritis) compared with 27 of 91 taking placebo (58.9\% versus $29.7 \%$ ). Psoriasis was also improved ${ }^{83}$ as assessed by Psoriasis Activity and Severity Index (PASI) score, target lesion response, SF-36, and the Dermatology Life Quality Index (DLQI). A 50\% improvement in PASI score (PASI 50) was achieved by $30.4 \%$ on leflunomide versus $18.9 \%$ on placebo. Significant improvements with lower response rates were also seen for PASI 75 and PASI 90 scores; target lesion response was $46.4 \%$ versus $25.3 \%$, and quality of life improvements were significantly greater with active treatment. These results indicate a moderate degree of improvement of psoriasis with leflunomide.

A small retrospective study compared duration of treatment with leflunomide and methotrexate in 44 patients with psoriatic arthritis in a rheumatology clinic. ${ }^{84}$ Loading doses were not given, and the doses were leflunomide 10-20 mg daily and methotrexate $7.5-15 \mathrm{mg} /$ week. At 24 months, $54.7 \%$ and $59 \%$ of patients, respectively, remained on the drug. There was a higher crude rate of adverse events in leflunomide users (38.7 per 100 patient-years) compared with methotrexate (14.3 events per 100 patient-years) and there was a trend towards more discontinuation for lack of efficacy with methotrexate (28.6\% versus $12.6 \%)$. Despite this relative lack of evidence, leflunomide is routinely used for psoriatic arthritis and other forms of inflammatory polyarthritis.

\section{Other inflammatory conditions}

Leflunomide has also shown benefit in a small open-label study in juvenile idiopathic arthritis ${ }^{85}$ and in a larger, randomized, controlled trial comparing it with methotrexate. ${ }^{86}$ Dosing was by body weight, with those over $40 \mathrm{~kg}$ receiving the full adult dose of $20 \mathrm{mg}$ daily and a $3 \times 100 \mathrm{mg}$ loading dose. For the primary outcome measure (a pediatric ACR 30 response) both treatments had a high response rate, but methotrexate was superior ( $89 \%$ versus $68 \%, P=0.02$ ). Leflunomide has also been investigated in small studies of systemic lupus erythematosus, ${ }^{87,88}$ Sjogren's syndrome, ${ }^{89}$ ankylosing spondylitis, ${ }^{90,91}$ dermatomyositis, ${ }^{92}$ and for treatment ${ }^{93}$ and remission maintenance ${ }^{94}$ in Wegener's granulomatosis. The results have been variable, and dosing and side effects do not differ among these indications.

\section{Safety and tolerability}

There is a large database on clinical safety issues with leflunomide. As with other DMARDs, side effects are fairly common, but most are mild and can be managed without discontinuation (Table 1). Side effects are most likely to occur early in treatment and do not appear to be more or less likely when leflunomide is used in combination with other DMARDs. The most common side effects are diarrhea, itchy maculopapular skin rash, reversible alopecia, and transient rises in liver enzyme test results. In Phase III trials, most side effects were mild to moderate, and occurred in the first six months of therapy, with a tendency for problems to diminish over time. ${ }^{37}$ More significant health problems related to leflunomide use are rarer, and include hypertension, bone marrow suppression, peripheral axonal neuropathy, interstitial pneumonitis, and teratogenicity.

\section{Hepatotoxicity}

Since its launch, there has been a steady stream of reports regarding fatal liver injury in association with leflunomide. A nested case-control study of 41,885 patients with RA dispensed a DMARD from two different claims databases concluded that leflunomide was no more likely to be associated with serious liver toxicity than methotrexate, and was less likely to cause hepatic injury than biologic DMARDs. ${ }^{95}$ The study did not find any increased association of nonserious hepatic events with leflunomide as compared with other DMARDs. An observational study of 101 RA patients treated with leflunomide for a mean of 10 (range 0.5-12) months found an incidence of 9\% for a rise in transaminases of 2-3 times the upper limit of the normal range (2-3× ULN). ${ }^{96}$ Reporting from the CORRUNA database, a recent study found an increased rate of liver enzyme rises when leflunomide is used with methotrexate, but not for leflunomide monotherapy compared with methotrexate. ${ }^{97}$ There were 1953 patients with RA and 151 with psoriatic arthritis in the study. In RA, rises in alanine aminotransferase (ALT) or aspartate aminotransferase (AST) of 1-2× ULN occurred in $14 \%-22 \%$ of patients treated with methotrexate, leflunomide, or other DMARD monotherapy, but occurred in 31\% of those on a methotrexate-leflunomide combination. Rises of $>2 \times$ ULN occurred in $5 \%$ of these patients. Analysis showed this increased risk was related to the dose of methotrexate (10-17.5 mg/week compared with $>20 \mathrm{mg} /$ week). Raised liver transaminases occurred in 35\% of patients using methotrexate for psoriatic arthritis, confirming previous observations that liver toxicity is more common in psoriasis, but there were insufficient patients with psoriatic arthritis treated with leflunomide for analysis.

In 2010, the FDA placed a "black boxed" warning for liver failure on the leflunomide datasheet. ${ }^{98}$ The committee reviewed 49 cases of severe liver injury between 2002 and 


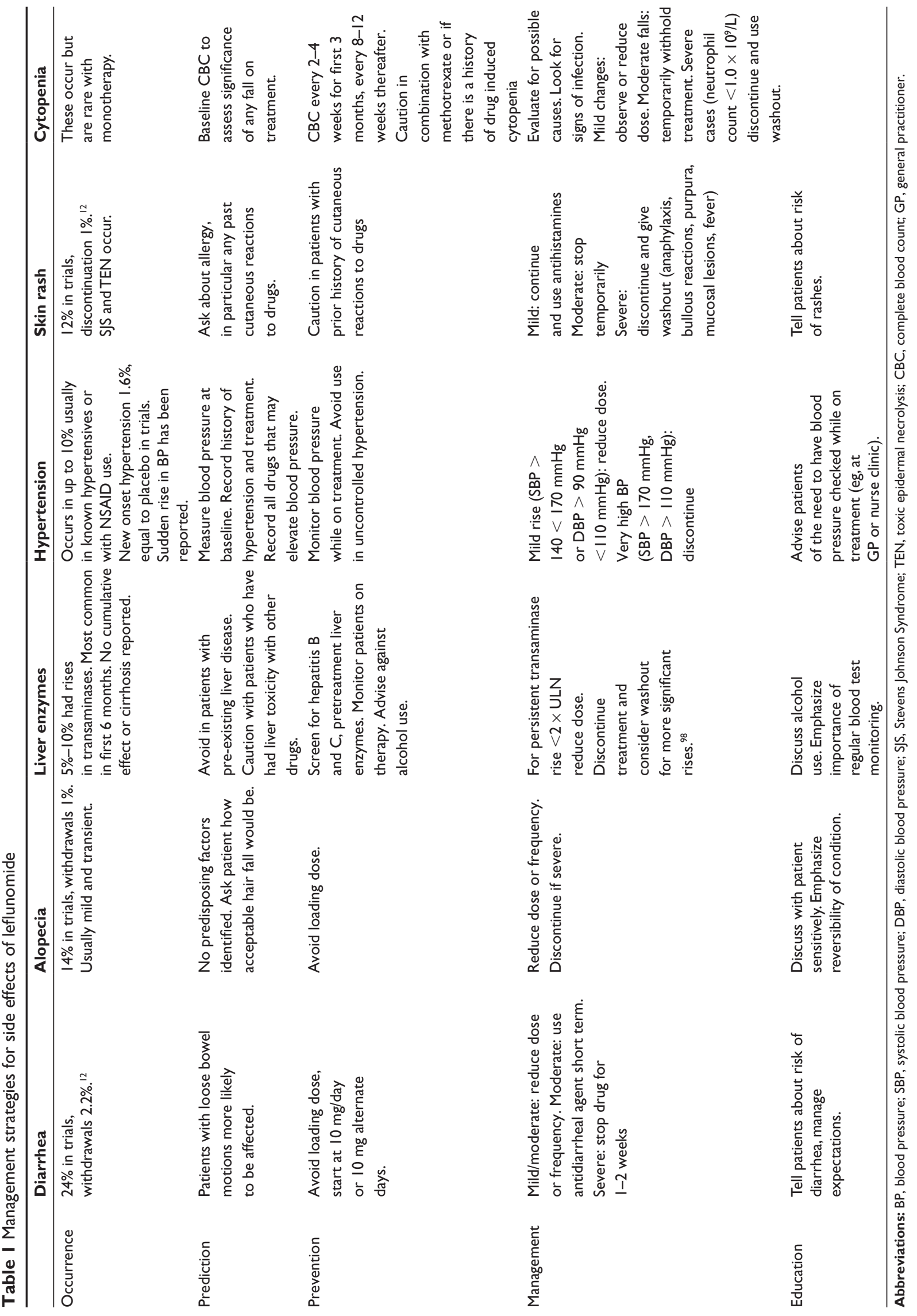


2009. There were 14 deaths, five patients who received a liver transplant, and a further nine who had a life-threatening episode. Jaundice, coagulopathy, or encephalopathy was described in another 11 cases, and the remaining patients had other milder manifestations of liver toxicity, such as rash, itch, vomiting, abdominal pain, and fever. Seventeen of the 49 patients had normal liver enzymes before starting leflunomide. In 46 of the 49 cases, patients were also taking drugs with known liver toxicity, including methotrexate, anti-TNF agents, hydroxychloroquine, NSAIDs, or acetaminophen. The FDA advises that patients with ALT values $>2 \times$ ULN should not be given leflunomide, and that leflunomide should be stopped, and a washout procedure considered in any patient in whom the ALT rises above $2 \times U L N$ while on treatment. This is consistent with current consensus statements for monitoring of patients on leflunomide endorsed by the ACR, although persistence of changes should be observed before instituting washout. ${ }^{99}$ Patients should be screened for hepatitis B and C prior to starting leflunomide, and particular care should be used when using leflunomide in combination with other drugs with known hepatotoxicity. ${ }^{99}$ As with methotrexate, it is also appropriate to advise patients to drink a minimum of alcohol while using leflunomide.

\section{Interstitial pneumonitis}

The association of leflunomide with acute interstitial pneumonitis was first described in the Japanese literature, and it remains a problem that seems more common in this group. In a recent study of 5054 patients in Japan prospectively followed for the first 24 weeks of treatment, the incidence of newly developed or exacerbated interstitial lung disease in RA patients was $1.2 \%{ }^{100}$ Pre-existing interstitial lung disease, cigarette smoking, body weight less than $40 \mathrm{~kg}$, and use of a loading dose emerged as independent risk associations in multivariate analysis. As with other causes of acute pneumonitis, there is a high case fatality rate. In one study, nine of 22 patients died, and profound hypoxemia, a low serum albumin, a high serum C-reactive protein level, and failure of recovery of lymphocytopenia were associated with poor outcome. ${ }^{101}$

A number of other groups have reported on leflunomide and pneumonitis, but because these are mostly retrospective case series or summaries of spontaneous adverse event reporting, there are problems of confounding and bias. Adjudication of cases also caused significant difficulty because, in many cases, the clinical presentation was not well described and other causes were not always excluded. In almost all cases, methotrexate is also implicated, although the occurrence of the problem in close temporal proximity to starting leflunomide is recognized. In a nested case-control study of 62,734 RA patients treated with DMARDs, there were 74 cases of acute pneumonitis. Compared with DMARD controls, there was a relative risk of 1.9 for developing pneumonitis when taking leflunomide. ${ }^{102}$ There was no increased risk with leflunomide when patients exposed to methotrexate or who had pre-existing interstitial lung disease were excluded. A recent review has brought some clarity. ${ }^{103}$ From a literature search, 32 cases were identified satisfying adjudication criteria, and $19 \%$ of patients died. In all of the cases, the patients had either a prior history of interstitial lung disease or had taken methotrexate and, in 44\%, methotrexate was being used in combination with leflunomide. Although there was a tendency for pneumonitis to occur earlier if a loading dose was used, it did not appear that use of a loading dose increased the likelihood of this complication. Cholestyramine washout did not affect outcome. In all cases the patients had RA, and pneumonitis has not been described in patients using leflunomide for other indications. It seems likely that leflunomide, like other immunomodulatory agents, including the anti-TNF agents, increases the likelihood of pneumonitis associated with RA. Leflunomide does not seem to be associated with slowly progressive lung fibrosis or other pulmonary side effects, although there are isolated reports of pulmonary nodulosis. ${ }^{104,105}$

\section{Hypertension}

Hypertension has been commonly reported as a side effect of leflunomide. In the Phase II study it occurred in up to $10.6 \%$ of patients given the $25 \mathrm{mg}$ daily dose. ${ }^{6}$ New onset of hypertension occurred in the Phase III clinical trials in $2.1 \%-3.7 \%$ of patients, and mean increases in systolic and diastolic blood pressures were $2.2 \mathrm{mmHg}$ and $1.9 \mathrm{mmHg}$, respectively. ${ }^{8,25,34}$ These changes were not associated with renal dysfunction or proteinuria. Various mechanisms have been suggested, including displacement of NSAIDs from protein binding sites and an increase in sympathetic drive. ${ }^{106}$ In a prospective study of 30 patients treated with the standard treatment algorithm, a significant rise in systolic blood pressure from a mean of $127 \mathrm{mmHg}$ to $134 \mathrm{mmHg}$ occurred within 2-4 weeks. ${ }^{107}$ Mean diastolic blood pressure did not increase significantly, but in one patient a rise of $40 \mathrm{mmHg}$ systolic and $20 \mathrm{mmHg}$ diastolic blood pressures were noted. Therefore, it is advisable that blood pressure be monitored, particularly in the first few weeks of treatment. 


\section{Neuropathy}

Central nervous system side effects reported in clinical trials include dizziness $(4 \%)$, headaches $(7 \%)$, and paresthesiae (2.9\%). While paresthesiae were more common with leflunomide than with sulfasalazine or with placebo, the incidence was similar in patients taking methotrexate. Peripheral neuropathy, specifically a sensory axonal neuropathy, has been suggested as a side effect of leflunomide in several case reports ${ }^{108-111}$ and in a retrospective case series of 785 patients that suggested a prevalence of $1.4 \% .{ }^{12}$ It has occurred in patients treated for RA and psoriatic arthritis. In a review of 80 cases reported to the FDA, symptoms developed most commonly within six months of starting leflunomide (range three days to three years). Nerve conduction studies in 37 cases showed a distal axonal sensory or sensorimotor polyneuropathy, and recovery was usual on stopping the drug. ${ }^{113} \mathrm{~A}$ prospective observational study of 113 patients with RA treated with leflunomide found eight incident cases and two cases of exacerbated peripheral neuropathy. ${ }^{114}$ Thirty percent of cases had concomitant diabetes compared with $2.9 \%$ for those without neuropathy, and potentially neurotoxic drugs were in use by another $20 \%$ versus $1.9 \%$. In a prospective cohort study of 16 patients treated with leflunomide and 32 RA patients treated with other DMARDs followed for six months, peripheral neurologic symptoms were specifically sought, and all patients underwent nerve conduction studies. An increase in neurologic symptoms was reported in $54 \%$ of the leflunomide group versus $8 \%$ of the control group. ${ }^{115}$ However, there was no correlation with the results of neuroelectrophysiologic studies. It can be concluded that paresthesiae are a fairly common side effect of leflunomide therapy, and that peripheral neuropathy remains a rare event with an uncertain causal relationship with leflunomide.

\section{Weight loss, diabetes}

Weight loss was reported in the original Phase II study, but has not been confirmed subsequently in trials. ${ }^{6}$ An observational study found that $7 \%$ of patients treated with leflunomide experienced significant weight loss $(8-20 \mathrm{~kg})$ that could not be explained. ${ }^{116}$ Cachexia sometimes occurs by an unknown mechanism. It does not correlate with diarrhea or nausea. Because DHODH is a mitochondrial enzyme, it is possible that leflunomide causes an increased metabolic requirement by uncoupling of oxidative phosphorylation, reducing the production of adenosine triphosphate. Weight loss is described as a common side effect in the data sheet. ${ }^{5}$
Diabetes is mentioned in the data sheet for leflunomide as occurring in $1 \%-3 \%$ of patients taking leflunomide in clinical trials, ${ }^{5}$ but published reports detailing this putative side effect are hard to find. Leflunomide has been used in experimental models of autoimmune diabetes and appears to be protective. Patients may ask about this possible complication, which does not seem to be a clinically significant problem.

\section{Bone marrow suppression}

Cytopenia is rare with leflunomide but bone marrow suppression has been reported, usually in association with other known causes, such as concomitant drug use and illness. There have been case reports of respiratory tract infections in patients taking leflunomide ${ }^{117-120}$ and of classical pulmonary tuberculosis ${ }^{121,122}$ but there are no reports of reactivation of latent tuberculosis. There may be an increase in susceptibility to infections, ${ }^{123-125}$ but there is no robust evidence to suggest these occur more frequently with leflunomide than in the general population of people with RA treated with nonbiologic DMARDs.

\section{Skin rash and wound healing}

Nonspecific itchy skin rash occurs with leflunomide and appears more likely in people with prior skin reactions to drugs. The incidence was $7.4 \%-24 \%$ compared with placebo rates of $4 \%-14 \%$ in trials. ${ }^{7,19,20}$ More serious skin reactions, including Stevens-Johnson syndrome and toxic epidermal necrolysis, have been reported rarely. ${ }^{5,126}$

There is uncertainty regarding the effect of leflunomide on wound healing and postoperative complications, because there are only a few conflicting reports. ${ }^{127}$ One observational study of 201 patients undergoing orthopedic procedures suggested that there were more postoperative complications and poor wound healing in patients treated with leflunomide. ${ }^{128}$ The study was nonrandomized and not blinded, and included a wide range of underlying conditions and treatment combinations. Another prospective randomized study in 82 patients showed no increased risk if leflunomide was continued rather than stopped prior to surgery. ${ }^{129}$ Therefore, it would be premature to conclude that leflunomide should be discontinued routinely for patients undergoing surgery.

\section{Use of leflunomide in clinical practice Retention on leflunomide}

The length of time a patient stays on a DMARD is an accepted clinical indicator of effectiveness, although it is influenced by a number of factors that introduce bias. ${ }^{130}$ In the six-month 
and 12-month Phase III trials, retention on leflunomide ranged from $17 \%$ to $44 \%$, but annualized rates (eg, per 100 patient-years) were not given. ${ }^{8,24,26,44}$ In the extension studies, retention rates were higher $(82 \%-85 \%)$ but patients were reenrolled into the studies, so those patients who were intolerant or partially responsive may have chosen not to continue. ${ }^{33,34}$ Because the data were prospectively gathered in randomized patient groups, there is some reassurance regarding tolerability with long-term use. Responses in clinical trials are not usually replicated in real-life clinical situations, so information from postmarketing studies is very relevant.

There have been several postmarketing cohort studies that have examined the length of time patients remain on leflunomide treatment, ${ }^{96,131-137}$ all of which have found higher rates of discontinuation than those observed in clinical trials. In a multicenter case series of 136 patients followed for a median 317 days, the discontinuation rate was 56.2 per 100 patient-years. ${ }^{136}$ Twenty-nine percent of patients stopped for an adverse event and 13\% because of lack of efficacy. In a subsequent study, this group reported on 279 patients started on leflunomide in whom $62 \%$ discontinued in the treatment period (annualized discontinuation rate was not given). Using multivariate analysis, a strong effect was seen for "attending rheumatologist", suggesting that physician behavior in response to side effects is an important determinant. $^{135}$

A study in France followed 116 patients over three years. The discontinuation rate was $70 \%$ at one year, being $32 \%$ because of an adverse event and $22 \%$ for lack of efficacy. ${ }^{133}$ An observational retrospective study using the US Veterans Affairs database, which involved 3325 predominantly male patients over 33 months, reported a discontinuation rate of $42 \%$ and found an association with use of a loading dose. ${ }^{134}$

In another observational study in two centers, leflunomide was compared with sulfasalazine and methotrexate in 1088 patients, comprising 5141 patient-years of DMARD exposure. ${ }^{132}$ Time to discontinuation was studied using KaplanMeier analysis, and showed that duration of treatment was longer for methotrexate (median 28 months versus 20 months for leflunomide or sulfasalazine). The overall discontinuation rate was 55\% after two years of follow-up, and another retrospective postmarketing study found a withdrawal rate of $26 \%$ at 30 months. $^{131}$

In a national postmarketing surveillance study in New Zealand, 318 patients were prospectively enrolled and followed for two years. ${ }^{137}$ The discontinuation rate was $36 \%$ at one year and $50 \%$ at two years. Overall, these observational studies show that leflunomide is an effective treatment in the clinic, with about $50 \%$ of patients remaining on treatment long term.

\section{Leflunomide in the elderly and in early RA}

Leflunomide is well tolerated and effective in elderly people with RA and psoriatic arthritis. ${ }^{138}$ In a retrospective study of 90 people (10 with psoriatic arthritis), 50 of whom were aged over 65 years, discontinuation rates at 24 months were $34 \%$ in those under 65 and $32.5 \%$ in the older group. There were no differences based on leflunomide being used as monotherapy or in combination with other DMARDs, and there was no difference in the occurrence of or withdrawals due to adverse events.

The effectiveness of leflunomide in early RA was suggested by analyses of the Phase III clinical trials and confirmed in a recent prospective open-label study of people with disease duration less than one year. ${ }^{139}$ A DAS response was achieved in $71.9 \%$ at 12 weeks and $84.6 \%$ at 24 weeks, and $25 \%$ achieved remission by DAS28 criteria. Reported side effects were less frequent than in other studies in established disease ( $1 \%-3 \%$ experienced diarrhea, nausea, hypertension, or headache). These observations confirm previous observations that DMARDs are generally more effective and better tolerated in early RA.

\section{Use of a loading dose}

In the Phase III clinical trials of leflunomide as monotherapy, a loading dose of $100 \mathrm{mg}$ daily for three days was given, followed by a daily dose of $20 \mathrm{mg}$. Although this regimen results in a faster clinical response, the practice is widely believed to be associated with an increase in side effects, particularly liver enzyme rises, diarrhea, and hair fall. Attempting to avoid these problems, clinicians have used a variety of different loading regimes, but none has been formally studied in prospective randomized trials. Commonly, $100 \mathrm{mg}$ is dosed once weekly for three weeks, with a $20 \mathrm{mg}$ daily maintenance dose being used from the start, while many clinicians choose to use no loading dose at all.

The effect of a loading dose on tolerability was examined in an open-label extension to the Phase III trial of the combination with methotrexate described earlier in the text. ${ }^{49,50}$ Patients in the initial cohort received leflunomide $10 \mathrm{mg}$ daily after a loading dose, but those inadequately controlled on methotrexate-placebo were switched at 24 weeks to methotrexate-leflunomide without a loading dose. Side effects of nausea, diarrhea, and raised liver transaminases occurred less often in the group not given a loading dose..$^{50}$ 
In clinical practice it is now common not to use loading doses, but because this results in steady state of blood levels of leflunomide not being achieved for up to two months ${ }^{5}$ owing to its very long half-life, loading doses should probably be considered more often. The observation that clinical responses may not be maximal for up to six months, even with use of a loading dose ${ }^{51}$ suggests that a three-month trial of therapy may be insufficient. A registry study using hazard analysis found no effect of the use of a loading dose on retention on treatment with leflunomide, ${ }^{137}$ suggesting that the side effects, although more frequent, were easy to manage and acceptable to patients and prescribers in order to achieve a faster onset of action.

Methotrexate and leflunomide can also be started together; $72 \%$ achieved an ACR 20 at 20 weeks in one study. ${ }^{140}$ The usual dose for leflunomide in combination with methotrexate was $10 \mathrm{mg}$ in these studies; $39 \%$ of patients achieve an adequate clinical response. ${ }^{49}$ Depending on patient factors, such as tolerability, methotrexate dosing can either be maintained or reduced to $10 \mathrm{mg}$ weekly on starting leflunomide. However, the complexities of dosing in clinical practice have not been formally tested in a trial.

\section{Starting dose of leflunomide: $20 \mathrm{mg}$ versus $10 \mathrm{mg}$}

Initial dose-ranging studies used leflunomide $5 \mathrm{mg}, 10 \mathrm{mg}$ and $25 \mathrm{mg}$ daily; $20 \mathrm{mg}$ was determined as the optimum dose from modeling of the clinical response. ${ }^{5}$ Since then, only $20 \mathrm{mg}$ and $10 \mathrm{mg}$ daily have been used in trials. In one trial, a noninferiority design was used in 404 patients with RA. Following use of a loading dose, subjects received either $10 \mathrm{mg}$ or $20 \mathrm{mg}$ leflunomide daily. ${ }^{141}$ ACR response rates, HAQ DI, and individual clinical measures other than the swollen joint count were more improved by $20 \mathrm{mg}$ than by $10 \mathrm{mg}$ daily. Patients taking the lower dose also used a higher mean dosage of prednisolone and experienced more side effects and withdrawals for lack of efficacy. Although some patients will gain good control using the $10 \mathrm{mg}$ dose, more will gain benefit only at $20 \mathrm{mg}$. A dose of $5 \mathrm{mg}$ daily is not effective. The data support using an initial dose of $20 \mathrm{mg}$ daily in all patients on monotherapy, with the dose reduced to $10 \mathrm{mg}$ daily or $10 \mathrm{mg}$ alternated with $20 \mathrm{mg}$ daily if needed in order to improve tolerability. The effectiveness of these strategies has not been formally tested.

\section{Management of side effects Hepatotoxicity}

Liver enzyme changes (principally AST and ALT) may occur acutely or show a slower rise over time, and are often transient, resolving without dose adjustment of leflunomide. Alkaline phosphatase and gamma glutamyl transferase may also rise, but bilirubin is not usually affected. Changes in the ALT are of most concern. Rises that are up to $2 \times$ ULN do not necessarily require action but if the changes are persistent or if the ALT is $>2 \times$ ULN, leflunomide dose should be reduced or leflunomide may need to be stopped. The FDA Drug Safety Committee recommends using a washout procedure under these circumstances ${ }^{98}$ but, because most liver enzyme changes are transient and a washout procedure can result in a flare of rheumatoid disease activity that disadvantages the patient, this management decision requires careful consideration of the balance between safety and efficacy for the individual.

\section{Cytopenia}

Cytopenia (principally neutropenia) usually occurs gradually over time and can also resolve spontaneously or with dose reduction. Unlike sulfasalazine, leflunomide has not been associated with agranulocytosis. Cytopenia is uncommon with monotherapy and is more usually associated with combination therapy, especially with methotrexate. The issue for practice is which drug to reduce or stop in this situation, but there are no trials to inform this decision. Frequently it is the combination that causes the problem, individual drugs dosed separately being well tolerated. Dose changes with methotrexate are easier to make, but leflunomide levels fall slowly after dose reduction or stopping treatment. Because leflunomide is usually added to methotrexate, it is usual to adjust the leflunomide dose in this situation, but if methotrexate has only been partially effective it may be more logical to switch to leflunomide as monotherapy.

\section{Hypertension}

It is important to be aware of the association of leflunomide with hypertension. In clinical trials, $1.6 \%$ of patients had new onset of hypertension, a rate similar to placebo. However, the overall incidence of hypertension as a side effect is closer to $10 \%$. No studies have been done on the effect of dose reduction on blood pressure, but it is usually necessary to reduce dose or stop leflunomide, and prescribe antihypertensive agents to manage the problem. In clinical practice, leflunomide is often overlooked as a possible contributory factor to hypertension.

\section{Other side effects}

Hair fall, diarrhea, mild skin rashes, nausea, and paresthesiae may all improve with dose reduction. For some people, ongoing hair fall remains a problem necessitating cessation 
of therapy. However, in trials, methotrexate use is equally associated with hair fall, ${ }^{24}$ and active inflammatory disease can also cause hair loss. Diarrhea (looseness of stool) is usually mild, not associated with urgency, and is generally well accepted by patients. In some cases, however, diarrhea can be more extreme and only resolves on stopping treatment. As noted above, paresthesiae are relatively common and often respond to dose reduction. Peripheral neuropathy can be hard to ascribe to treatment and is often part of the underlying rheumatoid condition or concomitant diabetes; leflunomide should usually be reduced in dose or stopped because it may exacerbate the symptoms.

\section{Pregnancy}

Leflunomide is a known teratogen and is contraindicated in pregnancy (category X) and in breastfeeding, carrying a boxed warning in the US. Therefore, it should not be used in women wishing to become pregnant, and although the effect on male reproduction is unknown, this advice is extended to men. If leflunomide has been used within the two previous years, it is recommended that blood levels of teriflunomide be checked, and a washout procedure offered if detectable levels are found $(>0.02 \mathrm{mg} / \mathrm{L})$. In some countries it is hard to obtain blood levels and cost can be a barrier, in which case a washout procedure should be undertaken. Women who become pregnant by accident while on leflunomide should have a washout procedure and should also be counseled about the risks to fetal development.

There are many case reports of successful pregnancy outcome in this situation and so termination of pregnancy is not usually advised. A recent case-control study compared 64 pregnant women exposed to leflunomide, $95 \%$ of whom had cholestyramine washout, with 108 women with RA not treated with leflunomide and 78 healthy pregnant control subjects. ${ }^{142}$ Major structural defects were observed in three of 56 live births $(5.4 \%)$ in the leflunomide-exposed women compared with $4.2 \%$ in either control group. These rates are similar to those in the general population. Therefore, there was no evidence that leflunomide exposure increases the risk of adverse pregnancy outcome in women who undergo cholestyramine washout.

\section{Washout procedure}

In any case where there is significant harm associated with leflunomide, a washout procedure should be undertaken. Protocols using activated charcoal ( $50 \mathrm{~g}$ four times daily for 11 days) or cholestyramine ( $8 \mathrm{~g}$ three times daily for 11 days) can be used; dosing does not have to be on consecutive days.
A shorter regimen using cholestyramine $8 \mathrm{~g}$ three times daily for two days reduces plasma levels by $49 \%-65 \%{ }^{12}$ If this modified procedure is used, its effectiveness should be checked by measuring teriflunomide blood levels. In clinical practice, washout procedures and blood levels are done rarely, ${ }^{137}$ and there should probably be a greater use when managing severe reactions.

\section{Screening and monitoring patients on therapy}

Patients about to start leflunomide should have baseline tests similar to those for methotrexate and in practice most of these will have already been done because it is unusual to start leflunomide before methotrexate has been trialed. Complete blood count, liver enzymes, renal function, hepatitis B and C serology, HIV screen, and pregnancy test if indicated are recommended by ACR consensus guidelines at baseline. ${ }^{99}$ Full blood count and liver enzymes should be checked every 2-4 weeks in the first three months of treatment, every 8-12 weeks between three and six months, and every 12 weeks thereafter. More frequent testing is needed after an increase in dose or change in concomitant DMARD. ${ }^{99}$

\section{Summary}

Leflunomide has been in routine clinical use for RA and psoriatic arthritis for over a decade and can be considered a standard therapy. It shows efficacy and effectiveness similar to methotrexate when used as monotherapy, but its place in treatment should be after failure of methotrexate and before use of biologic DMARDs. It can be used as a combination therapy with methotrexate or sulfasalazine with enhanced efficacy where other DMARD therapy has been partially effective. It can be used in place of methotrexate in combination with anti-TNF DMARDs. In general, its side effect profile is similar to that of methotrexate, and it has a favorable risk/benefit ratio compared with other DMARDs. Postmarketing studies suggest that patients are likely to remain on leflunomide for at least as long as methotrexate. Leflunomide remains one of the most useful of the nonbiologic DMARDs for chronic inflammatory arthritis.

\section{Disclosure}

PJ was a clinical trials investigator in 1995-2000, an advisory board member in 1996-2002, and has received honoraria for speaking at industry-sponsored meetings. DW declares no conflicts of interest. 


\section{References}

1. Li EK, Tam LS, Tomlinson B. Leflunomide in the treatment of rheumatoid arthritis. Clin Ther. 2004;26(4):447-459.

2. Alcorn N, Saunders S, Madhok R. Benefit-risk assessment of leflunomide: An appraisal of leflunomide in rheumatoid arthritis 10 years after licensing. Drug Saf. 2009;32(12):1123-1134.

3. Bartlett RR, Dimitrijevic M, Mattar T, et al. Leflunomide (HWA 486), a novel immunomodulating compound for the treatment of autoimmune disorders and reactions leading to transplantation rejection. Agents Actions. 1991;32(1-2):10-21.

4. Fox RI. Mechanism of action of leflunomide in rheumatoid arthritis. Rheumatol Suppl. 1998;53:20-26.

5. Sanofi-Aventis. Arava Data Sheet [Package insert]. 2009. Available from; www.medsafe.govt.nz. Accessed 2010 Aug 30.

6. Mladenovic V, Domljan Z, Rozman B, et al. Safety and effectiveness of leflunomide in the treatment of patients with active rheumatoid arthritis. Results of a randomized, placebo-controlled, phase II study. Arthritis Rheum. 1995;38(11):1595-1603.

7. Beaman JM, Hackett LP, Luxton G, Illett KF. Effect of hemodialysis on leflunomide plasma concentrations. Ann Pharmacother. 2002;36(1): 75-77.

8. Smolen JS, Kalden JR, Scott DL, et al. Efficacy and safety of leflunomide compared with placebo and sulphasalazine in active rheumatoid arthritis: A double-blind, randomised, multicentre trial. European Leflunomide Study Group. Lancet. 1999;353(9149):259-266.

9. Panoulas VF, Douglas KMJ, Milionis HJ, et al. Serum uric acid is independently associated with hypertension in patients with rheumatoid arthritis. J Hum Hypertens. 2008;22(3):177-182.

10. Ruckemann K, Fairbanks LD, Carrey EA, et al. Leflunomide inhibits pyrimidine de novo synthesis in mitogen-stimulated T-lymphocytes from healthy humans. J Biol Chem. 1998;273(34): 21682-21691.

11. Fox RI, Herrmann ML, Frangou CG, et al. Mechanism of action for leflunomide in rheumatoid arthritis. Clin Immunol. 1999;93(3): 198-208.

12. Cohen S, Iqbal I. Leflunomide. Int J Clin Pract. 2003;57(2):6.

13. Pawlik A, Herczynska M, Kurzawski M, Safranow K, Dziedziejko V, Drozdzik M. The effect of exon (19C > A) dihydroorotate dehydrogenase gene polymorphism on rheumatoid arthritis treatment with leflunomide. Pharmacogenomics. 2009;10(2): 303-309.

14. Grabar PB, Rozman B, Logar D, Praprotnik S, Dolzan V. Dihydroorotate dehydrogenase polymorphism influences the toxicity of leflunomide treatment in patients with rheumatoid arthritis. Ann Rheum Dis. 2009;68(8):1367-1368.

15. Xu X, Blinder L, Shen J, et al. In vivo mechanism by which leflunomide controls lymphoproliferative and autoimmune disease in MRL/MpJ-lpr/ Ipr mice. J Immunol. 1997;159(1):167-174.

16. Cao WW, Kao PN, Aoki Y, Xu JC, Shorthouse RA, Morris RE. A novel mechanism of action of the immunomodulatory drug, leflunomide: Augmentation of the immunosuppressive cytokine, TGF-beta 1, and suppression of the immunostimulatory cytokine, IL-2. Transplant Proc. 1996;28(6):3079-3080.

17. Dimitrijevic M, Bartlett RR. Leflunomide, a novel immunomodulating drug, inhibits homotypic adhesion of mononuclear cells in rheumatoid arthritis. Transplant Proc. 1996;28(6):3086-3087.

18. Kraan MC, de Koster BM, Elferink JG, Post WJ, Breedveld FC, Tak PP. Inhibition of neutrophil migration soon after initiation of treatment with leflunomide or methotrexate in patients with rheumatoid arthritis: Findings in a prospective, randomized, doubleblind clinical trial in fifteen patients. Arthritis Rheum. 2000;43(7): 1488-1495.

19. Kraan MC, Reece RJ, Barg EC, et al. Modulation of inflammation and metalloproteinase expression in synovial tissue by leflunomide and methotrexate in patients with active rheumatoid arthritis. Findings in a prospective, randomized, double-blind, parallel-design clinical trial in thirty-nine patients at two centers. Arthritis Rheum. 2000;43(8):1820-1830.
20. Tchetverikov I, Kraan MC, van El B, Hanemaaijer R, DeGroot J, Huizinga TWJ. Leflunomide and methotrexate reduce levels of activated matrix metalloproteinases in complexes with alpha2 macroglobulin in serum of rheumatoid arthritis patients. Ann Rheum Dis. 2008;67(1):128-130.

21. Litinsky I, Paran D, Levartovsky D, et al. The effects of leflunomide on clinical parameters and serum levels of IL-6, IL-10, MMP-1 and MMP-3 in patients with resistant rheumatoid arthritis. Cytokine. 2006; 33(2):106-110.

22. Osiri M, Shea B, Robinson V, et al. Leflunomide for the treatment of rheumatoid arthritis: A systematic review and metaanalysis. J Rheumatol. 2003;30(6):1182-1190.

23. Osiri M, Shea B, Robinson V, et al. Leflunomide for treating rheumatoid arthritis. Cochrane Database Syst Rev. 2003;(1):CD002047.

24. Emery P, Breedveld FC, Lemmel EM, et al. A comparison of the efficacy and safety of leflunomide and methotrexate for the treatment of rheumatoid arthritis. Rheumatology (Oxford). 2000;39(6): 655-665.

25. Strand V, Cohen S, Schiff M, et al. Treatment of active rheumatoid arthritis with leflunomide compared with placebo and methotrexate. Leflunomide Rheumatoid Arthritis Investigators Group. Arch Intern Med. 1999;159(21):2542-2550.

26. Strand V, Tugwell P, Bombardier C, et al. Function and health-related quality of life: Results from a randomized controlled trial of leflunomide versus methotrexate or placebo in patients with active rheumatoid arthritis. Leflunomide Rheumatoid Arthritis Investigators Group. Arthritis Rheum.1999;42(9):1870-1878.

27. Whittle SL, Hughes RA. Folate supplementation and methotrexate treatment in rheumatoid arthritis: A review. Rheumatology (Oxford). 2004;43(3):267-271.

28. Prey S, Paul C. Effect of folic or folinic acid supplementation on methotrexate-associated safety and efficacy in inflammatory disease: A systematic review. Br J Dermatol. 2009;160(3): 622-628.

29. van Ede AE, Laan RF, Rood MJ, et al. Effect of folic or folinic acid supplementation on the toxicity and efficacy of methotrexate in rheumatoid arthritis: A forty-eight week, multicenter, randomized, double-blind, placebo-controlled study. Arthritis Rheum. 2001;44(7): 1515-1524.

30. Fransen J, Laan RFJM, van Der Laar MAFJ, Huizinga TWJ, van Riel PLCM. Influence of guideline adherence on outcome in a randomised controlled trial on the efficacy of methotrexate with folate supplementation in rheumatoid arthritis. Ann Rheum Dis. 2004;63(10): 1222-1226.

31. Dougados M, Emery P, Lemmel E-M, et al. Efficacy and safety of leflunomide and predisposing factors for treatment response in patients with active rheumatoid arthritis: RELIEF 6-month data. J Rheumatol. 2003;30(12):2572-2579.

32. Tugwell P, Wells G, Strand V, et al. Clinical improvement as reflected in measures of function and health-related quality of life following treatment with leflunomide compared with methotrexate in patients with rheumatoid arthritis: sensitivity and relative efficiency to detect a treatment effect in a twelve-month, placebo-controlled trial. Leflunomide Rheumatoid Arthritis Investigators Group. Arthritis Rheum. 2000;43(3):506-514.

33. Cohen S, Cannon GW, Schiff M, et al. Two-year, blinded, randomized, controlled trial of treatment of active rheumatoid arthritis with leflunomide compared with methotrexate. Utilization of Leflunomide in the Treatment of Rheumatoid Arthritis Trial Investigator Group. Arthritis Rheum. 2001;44(9):1984-1992.

34. Scott DL, Smolen JS, Kalden JR, et al. Treatment of active rheumatoid arthritis with leflunomide: Two year follow up of a double blind, placebo controlled trial versus sulfasalazine. Ann Rheum Dis. 2001;60(10): 913-923.

35. Kalden JR, Scott DL, Smolen JS, et al. Improved functional ability in patients with rheumatoid arthritis - longterm treatment with leflunomide versus sulfasalazine. European Leflunomide Study Group. J Rheumatol. 2001;28(9):1983-1991. 
36. Larsen A, Kvien TK, Schattenkirchner M, et al. Slowing of disease progression in rheumatoid arthritis patients during long-term treatment with leflunomide or sulfasalazine. Scand J Rheumatol. 2001; 30(3):135-142.

37. Kalden JR, Schattenkirchner M, Sorensen H, et al. The efficacy and safety of leflunomide in patients with active rheumatoid arthritis: A five-year followup study. Arthritis Rheum. 2003;48(6): 1513-1520.

38. US FDA, CDER, CBER, CDRH. Guidance for Industry. Clinical development programs for drugs, devices, and biological products for the treatment of rheumatoid arthritis (RA). 1999. Available from: http://www.fda.gov/downloads/Drugs/GuidanceComplianceRegulatoryInfor mation/Guidances/UCM071579.pdf. Accessed 2010 Jul 13.

39. Felson DT, Anderson JJ, Boers M, et al. American College of Rheumatology. Preliminary definition of improvement in rheumatoid arthritis. Arthritis Rheum. 1995;38(6):727-735.

40. Pinals RS, Masi AT, Larsen RA. Preliminary criteria for clinical remission in rheumatoid arthritis. Arthritis Rheum. 1981;24(10): 1308-1315.

41. van Gestel AM, Prevoo ML, van 't Hof MA, van Rijswijk MH, van de Putte LB, van Riel PL. Development and validation of the European League Against Rheumatism response criteria for rheumatoid arthritis. Comparison with the preliminary American College of Rheumatology and the World Health Organization/International League Against Rheumatism Criteria. Arthritis Rheum. 1996;39(1): 34-40.

42. Sesin CA, Bingham CO 3rd. Remission in rheumatoid arthritis: Wishful thinking or clinical reality? Semin Arthritis Rheum. 2005;35(3): 185-196.

43. van Riel P, Kalden J. Complete remission rates with leflunomide in rheumatoid arthritis: An analysis from the leflunomide global integrated database (GIDB). Ann Rheum Dis. 2003;62 Suppl 1:

44. Sharp JT, Strand V, Leung H, Hurley F, Loew-Friedrich I. Treatment with leflunomide slows radiographic progression of rheumatoid arthritis: Results from three randomized controlled trials of leflunomide in patients with active rheumatoid arthritis. Leflunomide Rheumatoid Arthritis Investigators Group. Arthritis Rheum. 2000;43(3): 495-505.

45. van der Heijde D, Kalden J, Scott D, Smolen J, Strand V. Long term evaluation of radiographic disease progression in a subset of patients with rheumatoid arthritis treated with leflunomide beyond 2 years. Ann Rheum Dis. 2004;63(6):737-739.

46. Pfeil A, Lippold J, Eidner T, et al. Effects of leflunomide and methotrexate in rheumatoid arthritis detected by digital X-ray radiogrammetry and computer-aided joint space analysis. Rheumatol Int. 2009;29(3):287-295.

47. Kremer JM. Methotrexate and leflunomide: Biochemical basis for combination therapy in the treatment of rheumatoid arthritis. Semin Arthritis Rheum. 1999;29(1):14-26.

48. Weinblatt ME, Kremer JM, Coblyn JS, et al. Pharmacokinetics, safety, and efficacy of combination treatment with methotrexate and leflunomide in patients with active rheumatoid arthritis. Arthritis Rheum. 1999; 42(7):1322-1328.

49. Kremer JM, Genovese MC, Cannon GW, et al. Concomitant leflunomide therapy in patients with active rheumatoid arthritis despite stable doses of methotrexate. A randomized, doubleblind, placebo-controlled trial. Ann Intern Med. 2002;137(9): 726-733.

50. Kremer J, Genovese M, Cannon GW, et al. Combination leflunomide and methotrexate (MTX) therapy for patients with active rheumatoid arthritis failing MTX monotherapy: Open-label extension of a randomized, double-blind, placebo controlled trial. J Rheumatol. 2004;31(8):1521-1531.

51. Dougados M, Emery P, Lemmel EM, Zerbini CAF, Brin S, van Riel P. When a DMARD fails, should patients switch to sulfasalazine or add sulfasalazine to continuing leflunomide? Ann Rheum Dis. 2005; 64(1):44-51.
52. Breedveld FC, Weisman MH, Kavanaugh AF, et al. The PREMIER study: A multicenter, randomized, double-blind clinical trial of combination therapy with adalimumab plus methotrexate versus methotrexate alone or adalimumab alone in patients with early, aggressive rheumatoid arthritis who had not had previous methotrexate treatment. Arthritis Rheum. 2006;54(1):26-37.

53. Klareskog L, van der Heijde D, de Jager JP, et al. Therapeutic effect of the combination of etanercept and methotrexate compared with each treatment alone in patients with rheumatoid arthritis: Double-blind randomised controlled trial. Lancet. 2004;363(9410):675-681.

54. Lipsky PE, van der Heijde DM, St Clair EW, et al. Infliximab and methotrexate in the treatment of rheumatoid arthritis. Anti-Tumor Necrosis Factor Trial in Rheumatoid Arthritis with Concomitant Therapy Study Group. N Engl J Med. 2000;343(22):1594-1602.

55. Weinblatt ME, Keystone EC, Furst DE, et al. Adalimumab, a fully human anti-tumor necrosis factor alpha monoclonal antibody, for the treatment of rheumatoid arthritis in patients taking concomitant methotrexate: The ARMADA trial. Arthritis Rheum. 2003;48(1): 35-45.

56. Finckh A, Simard JF, Duryea J, et al. The effectiveness of anti-tumor necrosis factor therapy in preventing progressive radiographic joint damage in rheumatoid arthritis: A population-based study. Arthritis Rheum. 2006;54(1):54-59.

57. Kristensen LE, Saxne T, Nilsson JA, Geborek P. Impact of concomitant DMARD therapy on adherence to treatment with etanercept and infliximab in rheumatoid arthritis. Results from a six-year observational study in southern Sweden. Arthritis Res Ther. 2006;8(6):R174.

58. Zink A, Listing J, Kary S, et al. Treatment continuation in patients receiving biological agents or conventional DMARD therapy. Ann Rheum Dis. 2005;64(9):1274-1279.

59. Combe B, Codreanu C, Fiocco U, et al. Etanercept and sulfasalazine, alone and combined, in patients with active rheumatoid arthritis despite receiving sulfasalazine: A double-blind comparison. Ann Rheum Dis. 2006;65(10):1357-1362.

60. O'Dell JR, Petersen K, Leff R, et al. Etanercept in combination with sulfasalazine, hydroxychloroquine, or gold in the treatment of rheumatoid arthritis. J Rheumatol. 2006;33(2):213-218.

61. Furst DE, Schiff MH, Fleischmann RM, et al. Adalimumab, a fully human anti tumor necrosis factor-alpha monoclonal antibody, and concomitant standard antirheumatic therapy for the treatment of rheumatoid arthritis: Results of STAR (Safety Trial of Adalimumab in Rheumatoid Arthritis). J Rheumatol. 2003;30(12): 2563-2571.

62. Burmester GR, Mariette X, Montecucco C, et al. Adalimumab alone and in combination with disease-modifying antirheumatic drugs for the treatment of rheumatoid arthritis in clinical practice: The Research in Active Rheumatoid Arthritis (ReAct) trial. Ann Rheum Dis. 2007; 66(6):732-739.

63. Kalden JR, Antoni C, Alvaro-Gracia JM, et al. Use of combination of leflunomide with biological agents in treatment of rheumatoid arthritis. J Rheumatol. 2005;32(8):1620-1631.

64. Bingham SJ, Buch MH, Kerr MA, Emery P, Valadao Barcelos AT. Induction of antinuclear antibodies in patients with rheumatoid arthritis treated with infliximab and leflunomide. Arthritis Rheum. 2004; 50(12):4072-4073.

65. Ibanez TC, Tayel YM, Criado BA, Sanz HA, Mola ME. Safety and efficacy of leflunomide and infliximab versus methotrexate and infliximab combination therapy in rheumatoid arthritis. Rheumatology (Oxford). 2005;44(11):1467-1468.

66. Flendrie M, Creemers MCW, Welsing PMJ, van Riel PLCM. The influence of previous and concomitant leflunomide on the efficacy and safety of infliximab therapy in patients with rheumatoid arthritis; a longitudinal observational study. Rheumatology (Oxford). 2005;44(4): 472-478.

67. Godinho F, Godfrin B, El Mahou S, Navaux F, Zabraniecki L, Cantagrel A. Safety of leflunomide plus infliximab combination therapy in rheumatoid arthritis. Clin Exp Rheumatol. 2004;22(3): $328-330$. 
68. Hansen KE, Cush J, Singhal A, et al. The safety and efficacy of leflunomide in combination with infliximab in rheumatoid arthritis. Arthritis Rheum. 2004;51(2):228-232.

69. Kalden JR, Nusslein HG, Wollenhaupt J, Burmester GR, Kruger K, Antoni C. Combination treatment with infliximab and leflunomide in patients with active rheumatoid arthritis: Safety and efficacy in an open-label clinical trial. Clin Exp Rheumatol. 2008;26(5):834-840.

70. Nordstrom DC, Konttinen L, Korpela M, et al. Classic disease modifying anti-rheumatic drugs (DMARDs) in combination with infliximab. The Finnish experience. Rheumatol Int. 2006;26(8):741-748.

71. Ortiz Garcia AM, Gonzalez-Alvaro I, Pardo RR, et al. Effectiveness and safety of infliximab combined with leflunomide in chronic polyarthritis. Clin Exp Rheumatol. 2004;22(6):790.

72. Perdriger A, Mariette X, Kuntz JL, et al. Safety of infliximab used in combination with leflunomide or azathioprine in daily clinical practice. J Rheumatol. 2006;33(5):865-869.

73. Kiely PDW, Johnson DM. Infliximab and leflunomide combination therapy in rheumatoid arthritis: An open-label study. Rheumatology (Oxford). 2002;41(6):631-637.

74. Finckh A, Dehler S, Gabay C, Doctors S. The effectiveness of leflunomide as a co-therapy of tumour necrosis factor inhibitors in rheumatoid arthritis: A population-based study. Ann Rheum Dis. 2009;68(1):33-39.

75. Strangfeld A, Hierse F, Kekow J, et al. Comparative effectiveness of tumour necrosis factor alpha inhibitors in combination with either methotrexate or leflunomide. Ann Rheum Dis. 2009;68(12):1856-1862.

76. de Stefano R, Frati E, Nargi F, et al. Comparison of combination therapies in the treatment of rheumatoid arthritis: Leflunomideanti-TNF-alpha versus methotrexate-anti-TNF-alpha. Clin Rheumatol. 2010;29(5):517-524.

77. Goldsmith CH, Boers M, Bombardier C, Tugwell P. Criteria for clinically important changes in outcomes: Development, scoring and evaluation of rheumatoid arthritis patient and trial profiles. OMERACT Committee. J Rheumatol. 1993;20(3):561-565.

78. Henes JC, Schedel J, Kanz L, Koetter I. Rituximab and concomitant leflunomide for the treatment of rheumatoid arthritis. Rheumatol Int. 2010;30(5):709-712.

79. Gabay C, Chatzidionysiou K, Nasonov E, et al. Effectiveness of different DMARD co-therapies in rituximab-treated rheumatoid arthritis (RA) patients - results of a one-year follow up study from the Cerrera collaboration. Ann Rheum Dis. 2010;69(S3):1.

80. Karanikolas G, Charalambopoulos D, Vaiopoulos G, et al. Adjunctive anakinra in patients with active rheumatoid arthritis despite methotrexate, or leflunomide, or cyclosporin-A monotherapy: A 48-week, comparative, prospective study. Rheumatology (Oxford). 2008;47(9):1384-1388.

81. Botsios C, Sfriso P, Furlan A, et al. Anakinra, a recombinant human IL-1 receptor antagonist, in clinical practice. Outcome in 60 patients with severe rheumatoid arthritis. Reumatismo. 2007;59(1):32-37. Italian.

82. Kaltwasser JP, Nash P, Gladman D, et al. Efficacy and safety of leflunomide in the treatment of psoriatic arthritis and psoriasis: A multinational, double-blind, randomized, placebo-controlled clinical trial. Arthritis Rheum. 2004;50(6):1939-1950.

83. Nash P, Thaci D, Behrens F, Falk F, Kaltwasser JP. Leflunomide improves psoriasis in patients with psoriatic arthritis: An in-depth analysis of data from the TOPAS study. Dermatology. 2006;212(3):238-249.

84. Malesci D, Tirri R, Buono R, La Montagna G. Leflunomide in psoriatic arthritis: A retrospective study of discontinuation rate in daily clinical practice compared with methotrexate. Clin Exp Rheumatol. 2007;25(6):881-884.

85. Silverman E, Spiegel L, Hawkins D, et al. Long-term open-label preliminary study of the safety and efficacy of leflunomide in patients with polyarticular-course juvenile rheumatoid arthritis. Arthritis Rheum. 2005;52(2):554-562.

86. Silverman E, Mouy R, Spiegel L, et al. Leflunomide or methotrexate for juvenile rheumatoid arthritis. $N$ Engl J Med. 2005;352(16): 1655-1666.
87. Remer CF, Weisman MH, Wallace DJ. Benefits of leflunomide in systemic lupus erythematosus: A pilot observational study. Lupus. 2001; 10(7):480-483.

88. Tam LS, Li EK, Wong CK, Lam CWK, Szeto CC. Double-blind, randomized, placebo-controlled pilot study of leflunomide in systemic lupus erythematosus. Lupus. 2004;13(8):601-604.

89. van Woerkom JM, Kruize AA, Geenen R, et al. Safety and efficacy of leflunomide in primary Sjögren's syndrome: A phase II pilot study. Ann Rheum Dis. 2007;66(8):1026-1032.

90. Haibel H, Rudwaleit M, Braun J, Sieper J. Six months open label trial of leflunomide in active ankylosing spondylitis. Ann Rheum Dis. 2005; 64(1):124-126.

91. van Denderen JC, van der Paardt M, Nurmohamed MT, de Ryck YMMA, Dijkmans BAC, van der Horst-Bruinsma IE. Double blind, randomised, placebo controlled study of leflunomide in the treatment of active ankylosing spondylitis. Ann Rheum Dis. 2005;64(12):1761-1764.

92. Boswell JS, Costner MI. Leflunomide as adjuvant treatment of dermatomyositis. J Am Acad Dermatol. 2008;58(3):403-406.

93. Bremer JP, Ullrich S, Laudien M, Gross WL, Lamprecht P. Methotrexate plus leflunomide for the treatment of relapsingWegener's granulomatosis. A retrospective uncontrolled study. Clin Exp Rheumatol. 2010;28 (1 Suppl 57):67-71.

94. Metzler C, Miehle N, Manger K, et al. Elevated relapse rate under oral methotrexate versus leflunomide for maintenance of remission in Wegener's granulomatosis. Rheumatology (Oxford). 2007;46(7): 1087-1091.

95. Suissa S, Ernst P, Hudson M, Bitton A, Kezouh A. Newer diseasemodifying antirheumatic drugs and the risk of serious hepatic adverse events in patients with rheumatoid arthritis. Am J Med. 2004;117(2):87-92.

96. van Roon EN, Jansen TLTA, Houtman NM, Spoelstra P, Brouwers JRBJ. Leflunomide for the treatment of rheumatoid arthritis in clinical practice: Incidence and severity of hepatotoxicity. Drug Saf. 2004;27(5):345-352.

97. Curtis JR, Beukelman T, Onofrei A, et al. Elevated liver enzyme tests among patients with rheumatoid arthritis or psoriatic arthritis treated with methotrexate and/or leflunomide. Ann Rheum Dis. 2010;69(1):43-47.

98. USFDA. Drug and Safety Communication: New boxed warning for severe liver injury with arthritis drug Arava (leflunomide). Available from; http://www.fda.gov/drugs/drugsafety/postmar ketdrugsafetyinformationforpatientsandproviders/ucm218679.htm\#data_summary. Accessed 2010 Jul 13.

99. Saag KG, Teng GG, Patkar NM, et al. American College of Rheumatology 2008 recommendations for the use of nonbiologic and biologic disease-modifying antirheumatic drugs in rheumatoid arthritis. Arthritis Rheum. 2008;59(6):762-884.

100. Sawada T, Inokuma S, Sato T, et al. Leflunomide-induced interstitial lung disease: prevalence and risk factors in Japanese patients with rheumatoid arthritis. Rheumatology (Oxford). 2009;48(9): 1069-1072.

101. Sato T, Inokuma S, Sagawa A, et al. Factors associated with fatal outcome of leflunomide-induced lung injury in Japanese patients with rheumatoid arthritis. Rheumatology (Oxford). 2009;48(10):1265-1268.

102. Suissa S, Hudson M, Ernst P. Leflunomide use and the risk of interstitial lung disease in rheumatoid arthritis. Arthritis Rheum. 2006;54(5):1435-1439.

103. Chikura B, Lane S, Dawson JK. Clinical expression of leflunomideinduced pneumonitis. Rheumatology (Oxford). 2009;48(9): 1065-1068.

104. Horvath IF, Szanto A, Csiki Z, Szodoray P, Zeher M. Intrapulmonary rheumatoid nodules in a patient with long-standing rheumatoid arthritis treated with leflunomide. Pathol Oncol Res. 2008;14(1):101-104.

105. Rozin A, Yigla M, Guralnik L, et al. Rheumatoid lung nodulosis and osteopathy associated with leflunomide therapy. Clin Rheumatol. 2006;25(3):384-388.

106. Panoulas VF, Metsios GS, Pace AV, et al. Hypertension in rheumatoid arthritis. Rheumatology (Oxford). 2008;47(9):1286-1298. 
107. Rozman B, Praprotnik S, Logar D, et al. Leflunomide and hypertension. Ann Rheum Dis. 2002;61(6):567-569.

108. Bharadwaj A, Haroon N. Peripheral neuropathy in patients on leflunomide. Rheumatology (Oxford). 2004;43(7):934.

109. Carulli MT, Davies UM. Peripheral neuropathy: An unwanted effect of leflunomide? Rheumatology (Oxford). 2002;41(8):952-953.

110. Kho LK, Kermode AG. Leflunomide-induced peripheral neuropathy. J Clin Neurosci. 2007;14(2):179-181.

111. van Riel PLCM, Smolen JS, Emery P, et al. Leflunomide: A manageable safety profile. J Rheumatol Suppl. 2004;71:21-4.

112. Metzler C, Arlt AC, Gross WL, Brandt J. Peripheral neuropathy in patients with systemic rheumatic diseases treated with leflunomide. Ann Rheum Dis. 2005;64(12):1798-1800.

113. Bonnel RA, Graham DJ. Peripheral neuropathy in patients treated with leflunomide. Clin Pharmacol Ther. 2004;75(6):580-585.

114. Martin K, Bentaberry F, Dumoulin C, et al. Peripheral neuropathy associated with leflunomide: Is there a risk patient profile? Pharmacoepidemiol Drug Saf. 2007;16(1):74-78.

115. Richards BL, Spies J, McGill N, et al. Effect of leflunomide on the peripheral nerves in rheumatoid arthritis. Intern Med J. 2007;37(2): 101-107.

116. Coblyn JS, Shadick N, Helfgott S. Leflunomide-associated weight loss in rheumatoid arthritis. Arthritis Rheum. 2001;44(5):1048-1051.

117. Berkowitz DM, Bechara RI, Wolfenden LL. An unusual cause of cough and dyspnea in an immunocompromised patient. Chest. 2007;131(5):1599-1602.

118. Ulusoy H, Bilgici A, Kuru O, Celenk C. Pulmonary abscess due to leflunomide use in rheumatoid arthritis: A case report. Rheumatol Int. 2005;25(2):139-142.

119. Bruyn GAW, Jansen TL, Ten Brinke A, de Vries M, Houtman PM, van Roon EN. Cavitating pneumonia, a severe complication of leflunomide therapy in chronic polyarthritis. Rheumatology (Oxford). 2007;46(3):553-554.

120. Uruga H, Izumi S, Hojo M, et al. A patient with Mycobacterium avium lung disease presenting with rapid, progressive and multiple cavity formation, who had been treated rheumatoid arthritis with disease modifying anti-rheumatic drugs (DMARDs). Nihon Kokyuki Gakkai Zasshi. 2008;46(3):195-201. Japanese.

121. Hocevar A, Rozman B, Praprotnik S, et al. Leflunomide-associated tuberculosis? Rheumatology (Oxford). 2006;45(2):228-229.

122. Agrawal S, Sharma A. Dual mycobacterial infection in the setting of leflunomide treatment for rheumatoid arthritis. Ann Rheum Dis. 2007;66(2):277.

123. Delank KS, Hansen T, Eysel P, Eckardt A. Infections of the musculoskeletal system with chronic polyarthritis during a combination therapy with Methotrexate and Leflunomide. Z Orthop Ihre Grenzgeb. 2002;140(5):555-560. German.

124. Grover R, Dhir V, Aneja R, et al. Severe infections following leflunomide therapy for rheumatoid arthritis. Rheumatology (Oxford). 2006;45(7):918-920.

125. Jenks KA, Stamp LK, O’Donnell JL, Savage RL, Chapman PT. Leflunomide-associated infections in rheumatoid arthritis. $J$ Rheumatol. 2007;34(11):2201-2203.

126. Teraki Y, Hitomi K, Sato Y, HamamatsuY, Izaki S. Leflunomide-induced toxic epidermal necrolysis. Int J Dermatol. 2006;45(11): 1370-1371.

127. Pieringer H, Stuby U, Biesenbach G. Patients with rheumatoid arthritis undergoing surgery: How should we deal with antirheumatic treatment? Sem Arthritis Rheum. 2007;36(5):278-286.

Open Access Rheumatology: Research and Reviews

\section{Publish your work in this journal}

Open Access Rheumatology: Research and Reviews is an international, peer-reviewed, open access journal, publishing all aspects of clinical and experimental rheumatology in the clinic and laboratory including the following topics: Pathology, pathophysiology of rheumatological diseases; Investigation, treatment and management of rheumatological
128. Fuerst M, Mohl H, Baumgartel K, Ruther W. Leflunomide increases the risk of early healing complications in patients with rheumatoid arthritis undergoing elective orthopedic surgery. Rheumatol Int. 2006;26(12):1138-1142.

129. Tanaka N, Sakahashi H, Sato E, Hirose K, Ishima T, Ishii S. Examination of the risk of continuous leflunomide treatment on the incidence of infectious complications after joint arthroplasty in patients with rheumatoid arthritis. J Clin Rheumatol. 2003;9(2):115-118.

130. Wolfe F, Michaud K, Stephenson B, Doyle J. Toward a definition and method of assessment of treatment failure and treatment effectiveness: The case of leflunomide versus methotrexate. J Rheumatol. 2003;30(8):1725-1732.

131. Pisoni L, Murgo A, Paresce E, Zeni S, Fantini F. Effectiveness and safety of leflunomide in the clinical practice. A different experience. Clin Exp Rheumatol. 2007;25(1):115; author reply 116.

132. Aletaha D, Stamm T, Kapral T, et al. Survival and effectiveness of leflunomide compared with methotrexate and sulfasalazine in rheumatoid arthritis: A matched observational study. Ann Rheum Dis. 2003;62(10):944-951.

133. Martin K, Bentaberry F, Dumoulin C, et al. Effectiveness and safety profile of leflunomide in rheumatoid arthritis: Actual practice compared with clinical trials. Clin Exp Rheumatol. 2005;23(1):80-84.

134. Siva C, Eisen SA, Shepherd R, et al. Leflunomide use during the first 33 months after food and drug administration approval: Experience with a national cohort of 3,325 patients. Arthritis Rheum. 2003;49(6):745-751.

135. van Roon EN, Hoekstra M, Tobi H, et al. Leflunomide in the treatment of rheumatoid arthritis. An analysis of predictors for treatment continuation. Br J Clin Pharmacol 2005;60(3):319-325.

136. van Roon EN, Jansen TLTA, Mourad L, et al. Leflunomide in active rheumatoid arthritis: A prospective study in daily practice. $\mathrm{Br} \mathrm{J}$ Clin Pharmacol. 2004;57(6):790-797.

137. White DHN, Lynskey NV, Jones PBB. Leflunomide use in New Zealand. A national prospective post-marketing study. Intern Med J. 2009;39(2):95-102.

138. Alivernini S, Mazzotta D, Zoli A, Ferraccioli G. Leflunomide treatment in elderly patients with rheumatoid or psoriatic arthritis: Retrospective analysis of safety and adherence to treatment. Drugs Aging. 2009;26(5):395-402

139. Kellner H, Bornholdt K, Hein G. Leflunomide in the treatment of patients with early rheumatoid arthritis-results of a prospective noninterventional study. Clin Rheumatol. 2010;29(8):913-920.

140. Lee SS, Park YW, Park JJ, et al. Combination treatment with leflunomide and methotrexate for patients with active rheumatoid arthritis Scand J Rheumatol. 2009;38(1):11-14.

141. Poor G, Strand V, Leflunomide Multinational Study G. Efficacy and safety of leflunomide $10 \mathrm{mg}$ versus $20 \mathrm{mg}$ once daily in patients with active rheumatoid arthritis: Multinational double-blind, randomized trial. Rheumatology (Oxford). 2004;43(6):744-749.

142. Chambers CD, Johnson DL, Robinson LK, et al. Birth outcomes in women who have taken leflunomide during pregnancy. Arthritis Rheum. 2010;62(5):1494-1503.

143. Strand V, Scott DL, Emery P, et al. Physical function and health related quality of life: Analysis of 2-year data from randomized, controlled studies of leflunomide, sulfasalazine, or methotrexate in patients with active rheumatoid arthritis. J Rheumatol. 2005;32(4):590-601. 